\title{
AN EXAMINATION OF PERSONALITY PAIRINGS TO IMPROVE VIDEO GAME ENJOYMENT
}

\author{
by \\ Gerry Chan \\ A thesis submitted to \\ the Faculty of Graduate and Postdoctoral Affairs \\ in partial fulfillment of the requirements for the degree of \\ Master of Arts \\ In \\ Human-Computer Interaction
}

\author{
Carleton University \\ Ottawa, Ontario \\ (C)2013 Gerry Chan
}




\begin{abstract}
Recently, a variety of research has been conducted to explore the value of video games for changing inactive lifestyles. The purpose of this study was to examine the effects of personality pairings on enjoyment within two gaming scenarios. The main goal is to prolong exercise interest in hopes to overcome the obesity endemic. It was hypothesized that one would enjoy playing with another possessing a personality type similar to their own. Subjective results showed that matched personality pairings particularly enjoyed playing in a competitive game scenario, males reported more enjoyment in competitive game compared to females, and friends enjoyed playing together more than strangers. Objective measures revealed that a competitive game scenario is more enjoyable than a cooperative game scenario, while number of rounds seemed to indicate that both game scenarios are equally enjoyable. To maximize enjoyment, recommendations for game design include encouraging social interaction between players and integration of a personality test before or during a multiplayer online game. Future research may evaluate other variables such as culture, and alternative personality pairing possibilities for increasing game enjoyment.
\end{abstract}




\section{Acknowledgements}

First, I would like to thank my supervisor, Dr. Anthony Whitehead, and co-supervisor, Dr. Avi Parush, for their valuable time and advice during the course of my thesis work.

In addition, I would like to thank all participants, including those who were part of the pilot test, for their time and participation in the experiment, as well as, those who generously aided in the recruitment of participants for the experiment.

Finally, I would like to thank my family for their patience, encouragement and support. 


\section{Table of Contents}

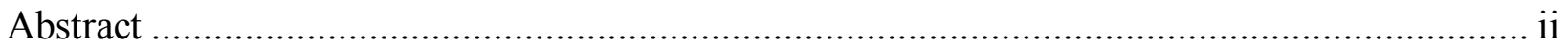

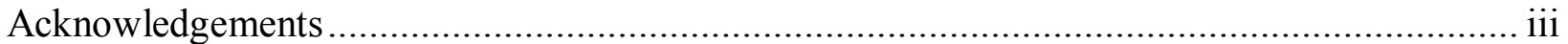

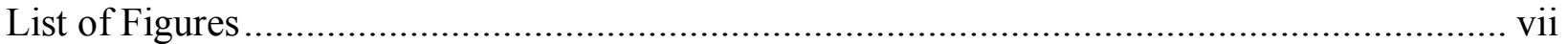

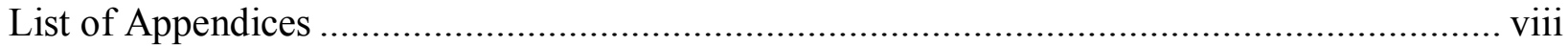

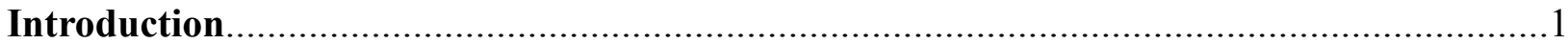

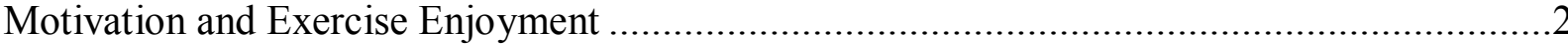

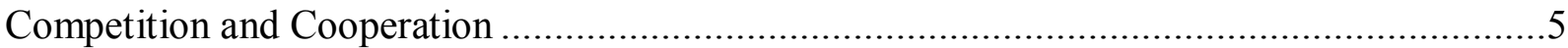

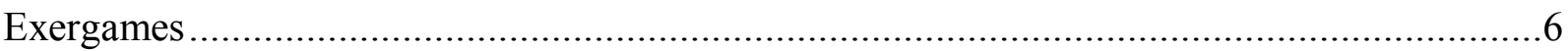

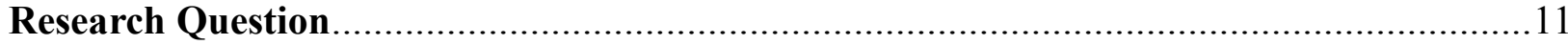

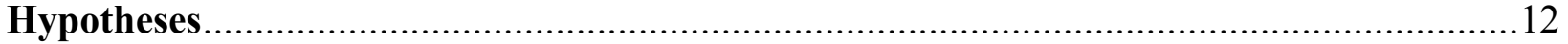

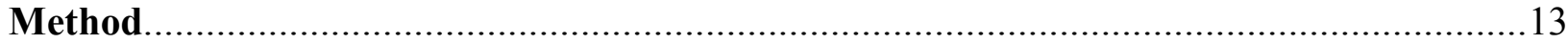

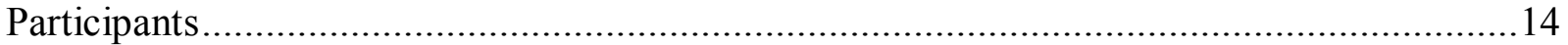

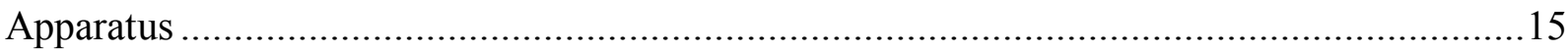

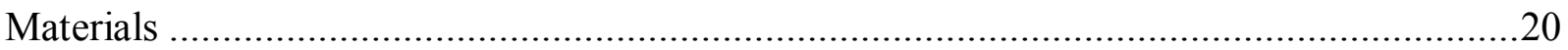

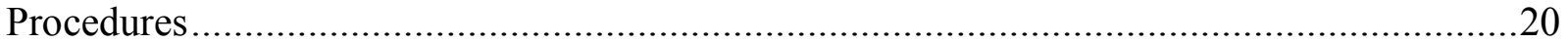

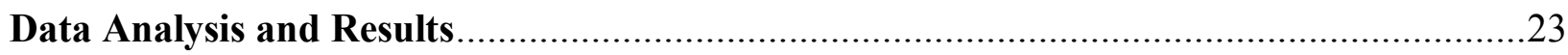

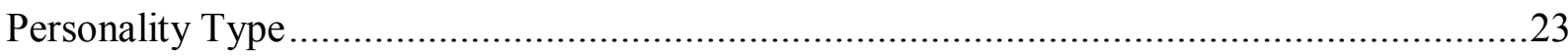

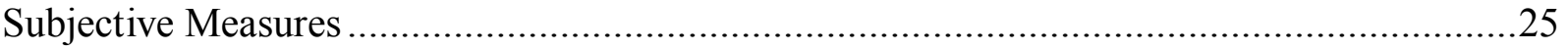

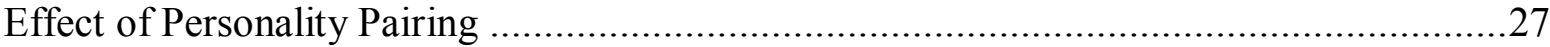

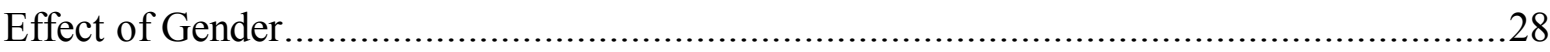

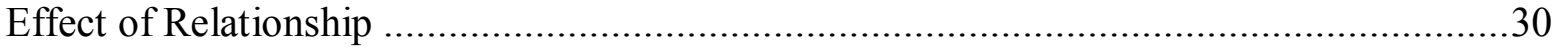

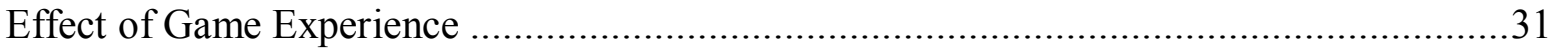

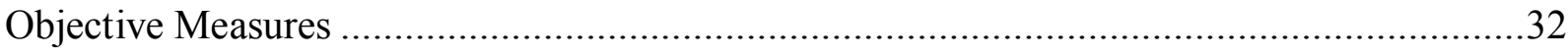

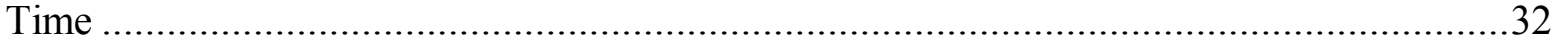

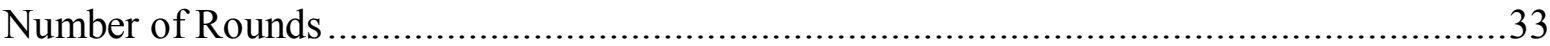

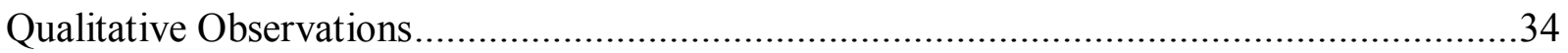




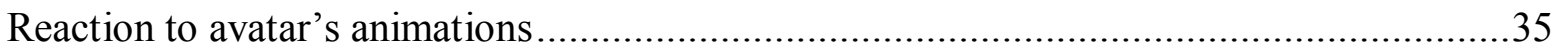

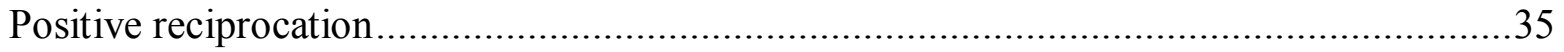

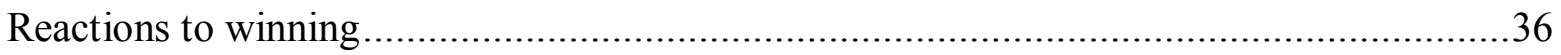

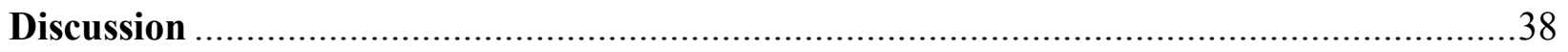

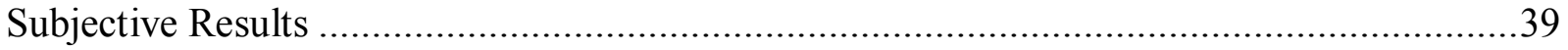

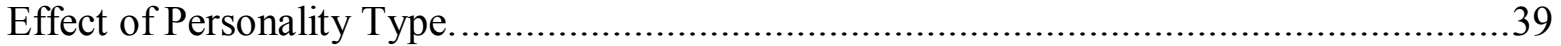

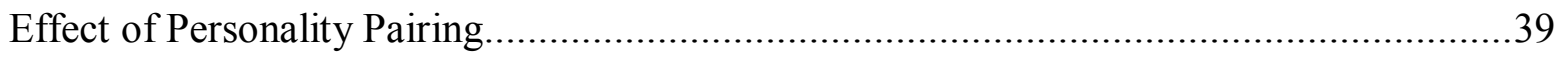

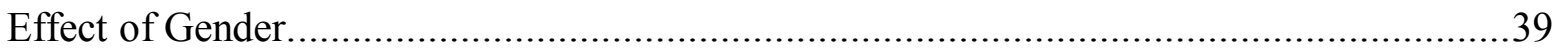

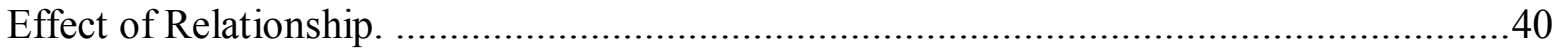

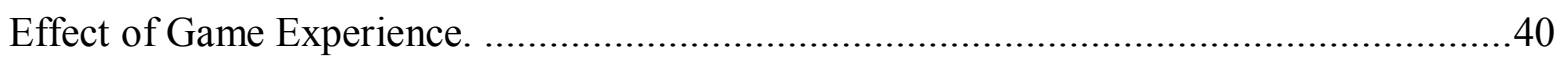

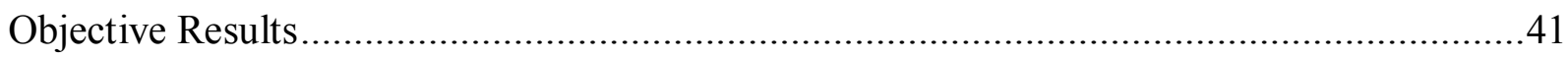

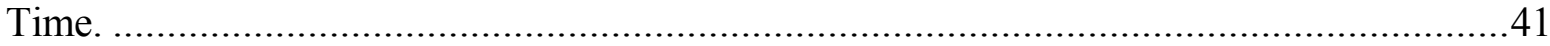

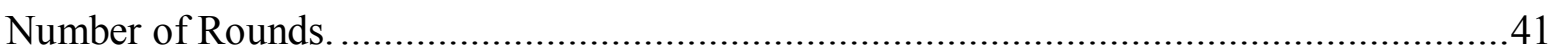

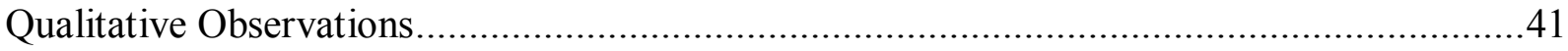

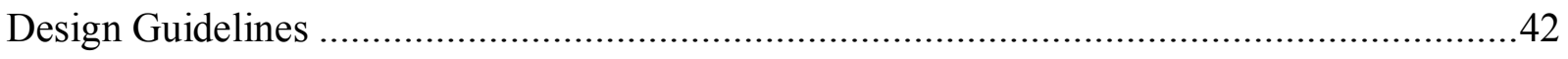

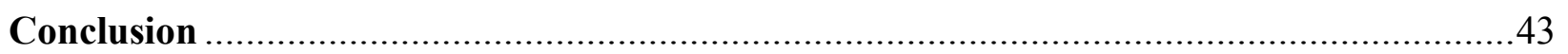

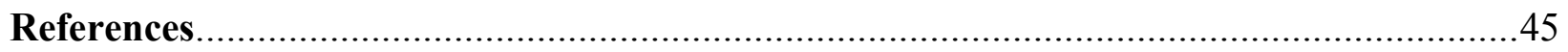

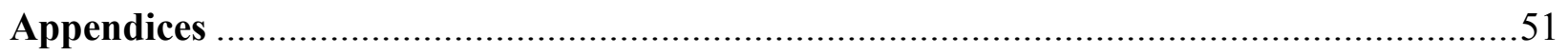




\section{List of Tables}

1 Motivational reasoning for exercise (Reeve, 2005)................. 2

2 Gender pairings with respect to personality pairings 14

3 Number of participant pairs who played in each game scenario with respect

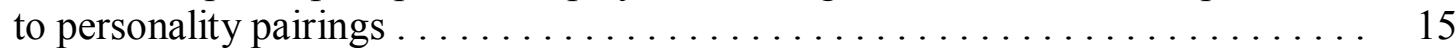

4 Equipment information and specifications $\ldots \ldots \ldots \ldots \ldots \ldots \ldots \ldots \ldots, 18$

5 Rationale for questions in post-game questionnaire (Appendix D) . . . . . . . 20

$6 \quad$ Example measures of expressions ........................ 22

$7 \quad$ Descriptive statistics for gender with respect to personality type $\ldots \ldots \ldots \ldots \ldots 25$

8 Number of personality pairings in three different categories ............. 25

9 Descriptive statistics for the level of agreement with respect to questions 2-17 (Part B) in the post-game questionnaire ................... 26

10 Statistically significant median test results for individual personality types with respect to level of agreement evaluated by part B in the post-game questionnaire (Appendix D) ..................................... 27

11 Table 11 Statistically significant Kruskal Wallis test results for personality pairings with respect to level of agreement evaluated by part B in the post-game questionnaire (Appendix D) . . . . . . . . . . . . . . . . . . 28

12 Statistically significant Mann-Whitney $U$ test results for gender differences with respect to level of agreement evaluated by part B in the post-game questionnaire

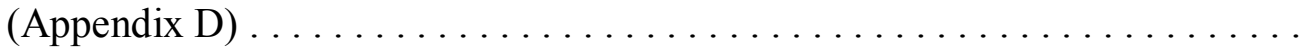

13 Statistically significant Kruskal Wallis test results for gender pairings with respect to level of agreement evaluated by part B in the post-game questionnaire

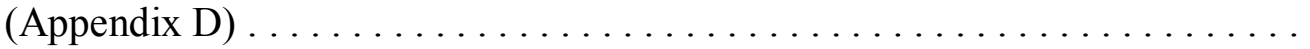

14 Mann-Whitney U tests for relationship with respect to personality parings in the

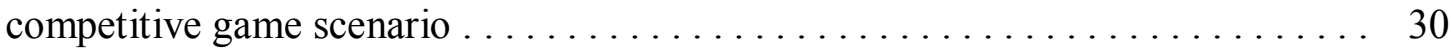

15 Mann-Whitney U tests for relationship with respect to personality parings in the cooperative game scenario . ............................

16 Marginally significant median test results for game experience with respect to level of agreement evaluated by part B in the post-game questionnaire (Appendix

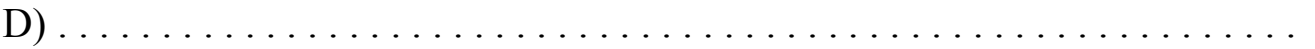

17 Average times (in seconds) for game scenarios with respect to personality

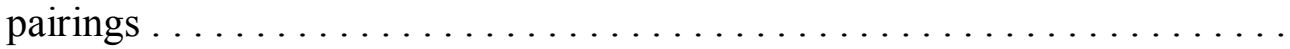

18 Average number of rounds for game scenarios with respect to personality

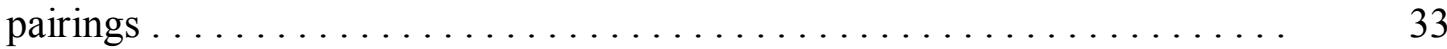

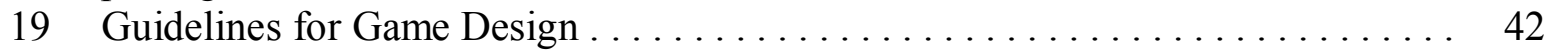




\section{List of Figures}

1 Sony Sports Champions front and back cover $\ldots \ldots \ldots \ldots \ldots \ldots \ldots \ldots \ldots$

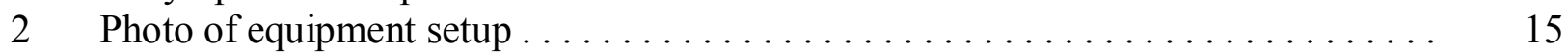

3 Schematic of experimental setup $\ldots \ldots \ldots \ldots \ldots \ldots \ldots \ldots \ldots \ldots \ldots \ldots \ldots \ldots$

4 Distributions of agreement level on a 5 point Likert scale $(1=$ never to $5=$ always $)$

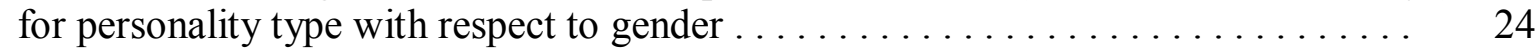

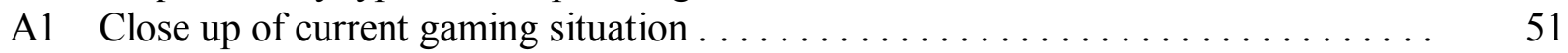

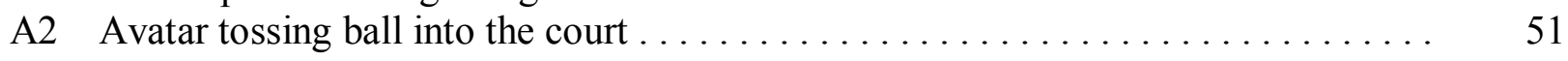

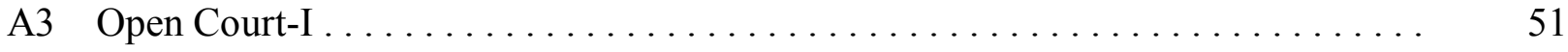




\section{List of Appendices}

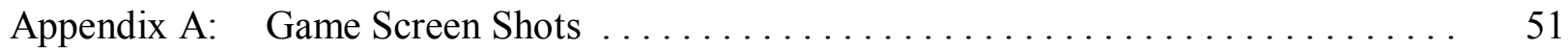

Appendix B: Social Game Study Recruitment Poster $\ldots \ldots \ldots \ldots \ldots \ldots \ldots \ldots . \quad 52$

Appendix C: Social Game Study E-mail Notice $\ldots \ldots \ldots \ldots \ldots \ldots \ldots \ldots \ldots \ldots . \ldots \ldots$

Appendix D: $\quad$ Post-Game Questionnaire ............................. 54

Appendix E: Game Scenario Information ........................... 61

Appendix F: $\quad$ Consent Form ................................. 62

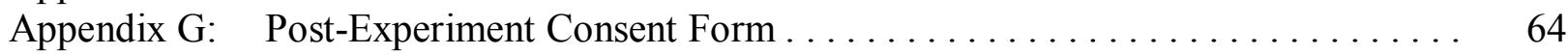

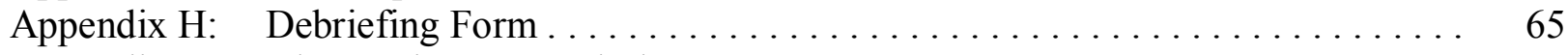

Appendix I: $\quad$ Observations Record Sheet ........................... 66

Appendix J: $\quad$ Usability Testing Script ............................... 67

Appendix K: $\quad$ Avatar Information .............................. 70

Appendix L: Histograms for Questions 2-17 (Part B) in Post-Game Questionnaire . . . . . 71 


\section{Introduction}

Regular exercise is an important aspect of maintaining good health (Alpert, 2009). The benefits of exercise can not only prevent cardiovascular disease and decrease the chances of type II diabetes (Bassuk \& Manson, 2005), but also improve sleep quality (Buman, Hekler, Bliwise, $\&$ King, 2010). However, the majority of people's daily activities, such as television watching, driving and working in an office environment are sedentary (Owen, Healy, Matthew, \& Dunstan, 2010). This makes integrating exercise into one's daily schedule hard. The primary reason why people do not engage in exercise is because they are too busy (Maitland \& Siek, 2009). Exercise can be defined as: "planned, structured, repetitive" movements (Caspersen, Powell, \& Christenson, 1985). Exercises such as jogging or running can feel tedious because they require long and continuous efforts. Perhaps changing the way people feel about doing exercise can make it fun.

"Exergames", the combination of video games and exercise (Sinclair, Hingston, \& Masek, 2007), aim to increase exercise motivation by offering a "safe, entertaining and engaging atmosphere" (Altamimi \& Skinner, 2012) for doing exercise and have gained much popularity because of their vast potential benefits. Not only are they able to make doing exercise entertaining, unobtrusively obtain measures regarding one's physical health (Staiano \& Calvert, 2011), but are also able to address a wide variety of health issues - from reducing diseases associated with childhood obesity (Koivisto, Merilampi, \& Kiili, 2011) to improving cognitive abilities in the aging population (Anderson-Hanley, Arciero, Brickman, Nimon, Okuma, Westen, Merz, Pence, Woods, Kramer, \& Zimmerman, 2012). Presently, most multiplayer video games are played in pairs and are typically competitive. Competition is important for experiencing game enjoyment (Vorderer, Hartmann, \& Klimmt, 2003). However, there has also been research suggesting that competition is enjoyable for highly-competitive individuals, but not for lowlycompetitive individuals (Song, Kim, Tenzek, \& Lee, 2009; Song, et al., 2013). This thesis examines the usefulness of video games and personality pairings for increasing exercise motivation. It also explores individual enjoyment with respect to one's personality type and gaming preferences. It was discovered that despite possessing a competitive or cooperative personality trait, a cooperative game was not a desirable scenario. Matched personality pairings 
and male pairings particularly favoured a competitive game scenario and friends enjoyed playing together more than strangers.

The subsequent sections are organized as follows. First, psychological concepts regarding human motivation and enjoyment will be described followed by the effects of competitive versus cooperative behaviours with respect to goal achievement. Then, literature concerning exergames and how the inclusion of competitive and competitive elements is able to increase exercise motivation will be presented. Next, the research question with eight hypotheses will be explained and a method to evaluate the effects of personality type and personality pairings with respect to game enjoyment will be provided. After, the results of the study will be revealed. Near the end, a general discussion about the implications of this experiment and guidelines for game design will be offered followed by some concluding remarks for future research.

\section{Motivation and Exercise Enjoyment}

In the psychology literature, human motivation is divided into two categories - intrinsic and extrinsic (Reeve, 2005). Intrinsic motivation is one's own willingness to perform a task simply because of sheer enjoyment. For example, children read because they enjoy reading. In contrast, extrinsic motivation requires external reward to encourage performance. For example, a student participates in class for bonus marks. With respect to exercise, an individual's motivation for doing it is multifaceted (Li, 1999; Ingledew, Markland, \& Ferguson, 2009). Adapted from Reeve (2005), Table 1 lists some of the reasons why one could be motivated to exercise, the source of the motivation, followed by an example.

Table 1

Motivational reasoning for exercise (Reeve, 2005)

\begin{tabular}{lll}
\hline Why Exercise? & Source of Motivation & Example \\
\hline For fun & Intrinsic motivation & $\begin{array}{l}\text { Children run and jump around the } \\
\text { school playground because it is fun. }\end{array}$ \\
To please others & Extrinsic motivation & $\begin{array}{l}\text { An athlete begins a new drill } \\
\text { because he/she was instructed by } \\
\text { his/her coach. }\end{array}$ \\
& & $\begin{array}{l}\text { Runners see if they can run } 5 \\
\text { ko accomplish a }\end{array}$ \\
goal & Goal oriented &
\end{tabular}




\begin{tabular}{lll}
$\begin{array}{l}\text { To meet a standard } \\
\text { of excellence }\end{array}$ & Achievement strivings & $\begin{array}{l}\text { A swimmer doing sprints to see if } \\
\text { he/she is able to beat his/her } \\
\text { previous time. }\end{array}$ \\
$\begin{array}{l}\text { To spend time with } \\
\text { friends }\end{array}$ & Positive affect & $\begin{array}{l}\text { Treating exercise as a social event } \\
\text { to spend time with friends }\end{array}$ \\
$\begin{array}{l}\text { Because it is } \\
\text { beneficial }\end{array}$ & Value & $\begin{array}{l}\text { People exercise to lose weight or } \\
\text { strengthen the heart. }\end{array}$ \\
\hline
\end{tabular}

Ryan, Frederick, Lepes, Rubio, \& Sheldon (1997) claim that because people's goals are concerned with outcomes extrinsic to the activity, motivation to engage in exercise are initially extrinsically focused for reasons such as fitness or appearance, it is intrinsic motivation which is important for continuation because it promotes feelings of competence and interest. More recently, Ryan, Williams, Patrick, and Deci (2009) argue that since humans are "active organisms" motivation to engage in exercise is for self-worth. They extended the meaning of intrinsic motivation and developed a broad model for understanding human motivation and personality called Self-Determination Theory (SDT; Deci \& Ryan, 2000). The model consists of three interrelated components with respect to one's primary psychological needs - competence, autonomy, and relatedness. "Competence" refers to the feeling of confidence both within the self and by receiving encouragement from others. "Autonomy" is an internal state which is regulated by the self. "Relatedness" refers to the sense of connectedness and acceptance by others. Essentially, one engages in exercise in order to satisfy these needs.

Murcia, Román, Galindo, Alonso, and González-Cutre (2008) conducted a study to examine the influence of peer relationships on exercise enjoyment. Three-hundred and ninetyfour non-competitive exercisers (238 males, 156 females) completed questionnaires to evaluate their perceptions of motivational climate of peers and basic psychological needs on enjoyment. Both task-involving peer motivational climate and needs for competence and relatedness positively predicted self-determined motivation. Likewise, self-determined motivation was also positively correlated with enjoyment. This study suggests that if peers express signs of support for competence, autonomy and relatedness, one will experience enjoyment and more motivation for doing exercise. Thus, supportive peers are important because they directly influence exercise adherence on the individual. 
In the context of exergames, Yim \& Graham (2007) indentified six critical requirements when designing exergames for encouraging exercise and created a prototype called "Life is a Village" (LIAV), which incorporates all six requirements. The first requirement is music to foster enjoyment during exercise. The second is the presence of a facilitator/instructor to lead and guide the activity. This is especially important for novice players because there is a model they can follow and someone to encourage their actions. The third is to provide achievable short and long-term goals. Begin with easy quests to build confidence and then, gradually introduce harder quests which take more time to complete. The fourth requirement is that the players' fitness level should be concealed from others. And finally the two remaining requirements deals with social aspects of play. In brief, the player should be given the opportunity to join groups and the gaming system should actively assist players in forming groups. In order to promote continuous exercise, LIAV was designed for a long-term commitment. Through cycling, players collected resources needed to build a village. Resources which were easy to collect required little time and effort, while the harder ones required more time and effort. LIAV is especially good for starters who wish to begin an exercise program. Currently, LIAV is still in the development process.

Penko and Barkley (2010) compared children of different body types - lean versus obese; and, playing preferences between Wii Sports Boxing exergame and a traditional sedentary video game (SVG). Twenty-four children between 8 to 12 years old participated in three different activity conditions - walking on a treadmill, Nintendo PunchOut!, and Wii Sports Boxing. They were asked to rate how much they enjoyed each activity on a $10 \mathrm{~cm}$ line anchored with markers from "do not like it at all" to "like it very much." Results showed that Wii Sports Boxing was the most favoured compared to the other two types of activity for both lean and obese children. This research is further evidence to suggest that exergames have the potential for increasing exercise motivation.

In one more study, Sun (in press) conducted a follow up study to examine the effectiveness of exergames for motivating physical activity during physical education class over a two semester period. Seventy grade 5 students ( 30 boys, 40 girls) rotated between eight different gaming stations to engage in a different full body movement games. Measures were obtained to assess physical intensity and situational interest. Results showed that physical 
activity increased over time; yet, interest declined. Moreover, boys reported experiencing more game enjoyment compared to girls. The conclusion of this study was that exergames may not be able to maintain exercise motivation in the long-term.

According to research presented in this section, there is still much uncertainty about whether or not video games are effective for increasing exercise motivation. The following section explores the practicality of competitive and cooperative elements within a video game for increasing exercise motivation.

\section{Competition and Cooperation}

From an evolutionary perspective, competitive behaviours are important for gathering resources necessary for survival of the individual; whereas cooperative behaviours are essential for survival of the group. Competition and cooperation are typically conceptualized as contrasting goal structures. Deutsch (1949) described competition and cooperation as social situations and proposed that there are three types of goal structures on the interdependence between individuals:

1. Competitive: one wins and the other loses (negative correlation)

2. Cooperative: both win (positive correlation)

3. Individual: goals are not connected in any way

From a psychological viewpoint, Deci, Betley, Kahle, Abrams, and Proac (1981) found that competition decreases intrinsic motivation. This is because the activity is perceived as an instrument to gain reward; yet, does not imply that competition does not motivate behaviour. More recently, Tauer and Harachiewicz (2004) conducted four field studies to examine the effects of pure cooperation, pure competition and intergroup competition on enjoyment in a sport setting. They found that intergroup competition resulted in most enjoyment and propose that instead of treating competition and cooperation as complete opposites, both are perhaps related. Unfortunately, limited research has been conducted to examine the influence of cooperation on motivation.

With respect to gender differences, research in an educational context has shown that females tend to favour cooperation while males lean more towards competition (Ahlgren \& Johnson, 1979). Stemming from the "male warrior hypothesis," - "the idea that "men's 
behaviours and cognitions are more intergroup oriented than women's" (Van Vugt, De Cremer, \& Janssen, 2007, p. 19) - more recent research suggests that males gravitate toward intergroup competition compared to females (Van Vugt, et al., 2007).

In the context of physical activity, Frederick-Recascino and Schuster-Smith (2003) found that the role of competition for experiencing enjoyment is consistent between athletes and noncompetitive exercisers. Two different groups of participants, competitive cyclists and general exercisers, completed surveys measuring motivation for physical activity, level of competitiveness within a sports setting and competitive-cooperative attitudes. Results showed for both groups, that sports-based competitiveness was positively correlated with higher levels of enjoyment and intrinsic motivation.

In the domain of video games, both competition and cooperation are typically available in multiplayer modes. In competitive mode, players play against each other; whereas in cooperative mode, players form a team and play against the computer. Research shows that integration of competitive elements is crucial for an enjoyable experience (Vorderer, et al., 2003). Not only is competition an important factor for enjoyment indoors, but also for playing outdoors within a mobile context (Olivereira \& Oliver, 2008). More recently, Schmierbach, Xu, Oeldorf-Hirsch, and Dardis (2012) further confirmed that competitive multiplayer video games are indeed enjoyable for two reasons - not only do they provide a social situation but also offer an effective type of competition. However, they reported that cooperative play was not as enjoyable compared to competitive play.

In relation to this thesis, it seems that competition and cooperation are worthwhile mechanisms for further exploration because from research presented in this section, both are able to increase human behaviour and motivate physical activity. The following section will focus on recent research that has been conducted concerning the effectiveness of competition and cooperation game modes for motivating play behaviour and supporting continuous exercise.

\section{Exergames}

Before visiting the literature regarding competitive and cooperative video games, two current reviews regarding the effectiveness of active video games (AVG) for increasing physical activity will be presented. AVG are "motion-based" games that rely on technology to detect a 
player's physical actions for manipulating objects in a virtual environment (Altamini, et al., 2012). Much research has taken on the idea and renamed AVG which integrates player exercise as "Exergames" (Altamimi, et al., 2012).

Peng, Crouse, and Lin (2012), reviewed forty-one published studies from 2002 to 2011 concerning the effectiveness of AVG for increasing physical activity in both children and adults. Based on their review, they concluded with four major implications. First they note that most exergames only offer moderate intensity exercise; and thus, are not the equivalent of traditional kinds of physical activities and sports. Second, with respect to body movements, some focus on lower parts of the body; some focus on upper parts; and, some require full body movements. The researchers have found evidence for AVGs that require full body movements, results in more energy expenditure compared to those that only focus on lower or upper body movements. Thirdly, AVG results in different outcomes for different populations. For example, the level of energy expenditure may be different for experienced players versus inexperienced players or perceived levels of enjoyment may vary for those who are overweight compared to those who are not. And finally, the level of energy expenditure is still unknown depending on different settings. For example, whether one is leisurely playing with friends at home, or playing competitively in a group environment.

Altamimi and Skinner (2012) also conducted an extensive review on the effectiveness of AVGs for increasing exercise motivation and consistent with the review above (Peng, et al., 2012), they also recommend that AVGs that promote full body movements are superior to ones that only require small localized body movements for getting better exercise. Furthermore, to address issues concerning childhood obesity, they suggest the importance of converting passive, sedentary games to active games. And although AVGs are not the same as conventional sports, they certainly have the potential to help overcome problems associated with childhood obesity.

Park, Yoo, Choe, Park and Song (2012) compared the differences between solitary exercises (one person running on a treadmill) versus social exergames (team racing on a treadmill presented with an interactive display) for effectiveness in expending energy and increasing motivation. The social exergame that was designed for comparison was called "Swan Boat." Swan Boat provides rich interaction between two players and encourages rigorous, 
synchronized movements between teammates during play. The "boat" metaphor is that each runner represents a pedal on each side of the boat and they must cooperate by adjusting speeds, omitting obstacles, and steering the right direction, in order to successfully reach a target destination. Twelve participants ( 8 males and 4 females) between 20 to 25 years of age were recruited to first run on an ordinary treadmill one week and then, Swan Boat the week after. Open-ended interview questions were administered after each running session. In general, participants reported that the interface was intuitive and the opportunity to cooperate and compete with another person during the game was an exciting experience.

As the researchers above demonstrated that competition increases motivation for exercise, Song, Kim, Tenzek, and Lee (2009) however, found that it is only effective for certain groups of individuals. They tested people who had different competitive natures (high versus low) in two different contextual settings (competition versus noncompetition). Seventy-six undergraduate students ( 38 males and 38 females) were asked to play hula hoop in Nintendo Wii Fit for a minimum of 10 minutes and using a 10-point Likert scale (strongly disagree to strongly disagree) measures of intrinsic motivation, self-efficacy, and self-perceived competitiveness were gathered for analysis. They found that those who are highly competitive, being situated in a competitive condition increased intrinsic motivation, but for those who were lowly competitive, exercising in a competitive setting resulted in negative effects on the exercising experience.

More recently, the same authors, Song, Kim, Tenzek, and Lee (2013) as mentioned in the previous literature, studied the role of competition for motivating exercise in the context of an exergame. Seventy-two participants (36 males and 36 females) were divided into high or low competitiveness based on a median split and randomly assigned to one of two conditions: competition or non-competition. In both conditions, participants watched a pre-recorded video clip of two confederates playing Wii Fit, Hula Hoop. The only difference between the two conditions was the presentation of ranking information. In the competition condition, ranking information was presented to reinforce effort and remind participants that a prize will be awarded to the winner, yet ranking information was absent in the non-competition condition. To evaluate intrinsic motivation levels, all participants were required to play for a minimum of 10 minutes, but may continue if they wished. Highly competitive individuals enjoyed playing in the competitive condition more so than the less competitive individuals. Furthermore, those who 
were less competitive continued playing much longer in the non-competitive condition compared to those in the competition condition suggesting that traces of intrinsic motivation were evident particularly for less competitive individuals who played in the non-competition condition. Based on these findings, the authors concluded that further research is needed to study the effects of competition on motivation in a video game context and suggested that game design should tailor to individual differences for increasing exercise motivation.

In a different study, Staiano, Abraham, \& Calvert (2012) examined the motivating effects of competitive versus cooperative exergame play for overweight and obese children. Thirty-one overweight African-American teenagers were randomly assigned to play Wii Active competitively or cooperatively during their spare time over a 6 month period. In the cooperative situation, players played together to accumulate points for calorie expenditure; while in the competitive situation, players competed independently against each other to earn points. To measure intrinsic motivation, qualitative observations were noted with respect to: sensory immersion, control/choice, challenge and social interaction. They found that cooperative play resulted in higher levels of intrinsic motivation than competitive play with respect to all motivation measures.

In one more study, Snyder, Anderson-Hanley, and Arciero (2012) investigated the effects of "social facilitation:" "the effect of the presence of others on the individual" (Bond Jr., 2001) on exercise intensity in three different scenarios: alone, with a virtual avatar, and a live person. Twenty-three female college students performed exercise on a virtual-reality-enhanced stationary bicycle in all three scenarios for two, 30 minute testing sessions. Results showed that competitive behaviours were highest when an individual was cycling with a live person. The authors point out that one's personality type should be considered when designing an exergame because they also found that competitive individuals were motivated more by a live competitor compared to less competitive individuals.

In another study, Peng and Hsieh (2012) studied the effects of goal structure (competition vs. cooperation) and relationship type (friends vs. strangers) on performance, motivation and commitment between players in a multiplayer online balloon popping game. In the competition condition, players competed against each other and whoever popped the most balloons won. For 
the cooperation condition, two players worked together popping balloons to achieve a team score. Results showed that a cooperative goal structure led to more motivation and commitment between friends compared to strangers.

Peng and Crouse (2013) further studied the effects of multiplayer modes in active video games by measuring enjoyment, physical exertion and motivation for future play with respect to the same or separate physical space. Participants played The Space Pop mini-game in Kinect Adventures three different ways: cooperatively in the same physical space, competitively with another person in separated physical space, and alone. Competitive play in a separated physical space promoted high enjoyment, physical exertion and motivation for future play. Additionally, participants reported that playing with another person is more enjoyable and motivational compared to playing alone. Yet, the researchers pointed out that the present study is not sufficient to determine the effects of competitive versus cooperative goal structures due to limitations of the game and playing space. In order to unravel the effect of goal structure (competitive vs. cooperative) and physical space co-presence (yes vs. no), they suggested that a game needs to be created to allow all four conditions.

Although informative, there has not yet been research conducted to explore the possible effects of pairing or combining individuals with similar and different personality types for increasing exercise interest within the context of a video game. Thus, the research study outlined in the next section aims to examine this idea. 


\section{Research Question}

The main goal of this project is to maintain exercise enjoyment. Video games attempt to hide the tedious aspects of exercise by presenting it as something fun and persuading one to do exercise. However, when the novelty (initial interest in a new technology) for a new game wears off, play is likely to fade due to decreased motivation, and consequently, exercise would also subside. Perhaps, if interest was preserved in the game, exercise would persist as well.

Playing together with another person can be more enjoyable and compatible personality pairings may be the key for motivating continuous play. Perhaps matching people with similar personality types could support compatibility between two individuals. Thus, this study investigates whether combining people of similar personality types is able to create an enjoyable and engaging game experience.

In short, the research question is: would pairing people with similar personality types increase exercise motivation within the context of a video game as opposed to random pairs of people? 


\section{Hypotheses}

The dependent variable of this study is enjoyment and the independent variables are two types of game scenarios: competition (1 human player versus 1 human player) and cooperation ( 2 human players versus 2 computer avatars). To maintain motivation for exercise, it was hypothesized that the presence of another individual (Zajonc, 1965) is necessary because it would increase enjoyment (Gajadhar, de Kort, \& IJsselsteijn, 2008). Furthermore, pairing people with similar personality types would also result in enjoyment. Yet, pairing people with dissimilar personality types would deter enjoyment. Below are 8 hypotheses:

H1: A competitive individual will enjoy playing with another competitive individual $\mathrm{H} 2$ : A cooperative individual will enjoy playing with another cooperative individual H3: A competitive individual will not enjoy playing with a cooperative individual H4: A cooperative individual will not enjoy playing with a competitive individual H5: A competitive individual will enjoy playing in a competitive game scenario H6: A cooperative individual will enjoy playing in a cooperative game scenario H7: A competitive individual will not enjoy playing in a cooperative game scenario H8: A cooperative individual will not enjoy playing in a competitive game scenario

To summarize, it was also hypothesized that matching personality type to game scenario will increase enjoyment. Individuals with competitive personalities will enjoy playing in a competitive game scenario more than in a cooperative scenario, and cooperative individuals will enjoy playing in a cooperative game scenario more than in a competitive scenario. 


\section{Method}

A video game called Bocce, found in Sports Champions (Figure 1) created by Sony Computer Entertainment America (Sports Champions, 2012) and Zindagi Games (Zindagi Games, 2013) was selected. "Bocce" is a ball tossing game. The game begins by one player tossing a "Pallino" (a small golden ball) into an empty court which sets a marker. Then, players try to toss larger balls, called Bocce, as close to the Pallino as they can. The person or team who tosses a Bocce closet to the Pallino wins. Appendix A shows some screen shots of the game.

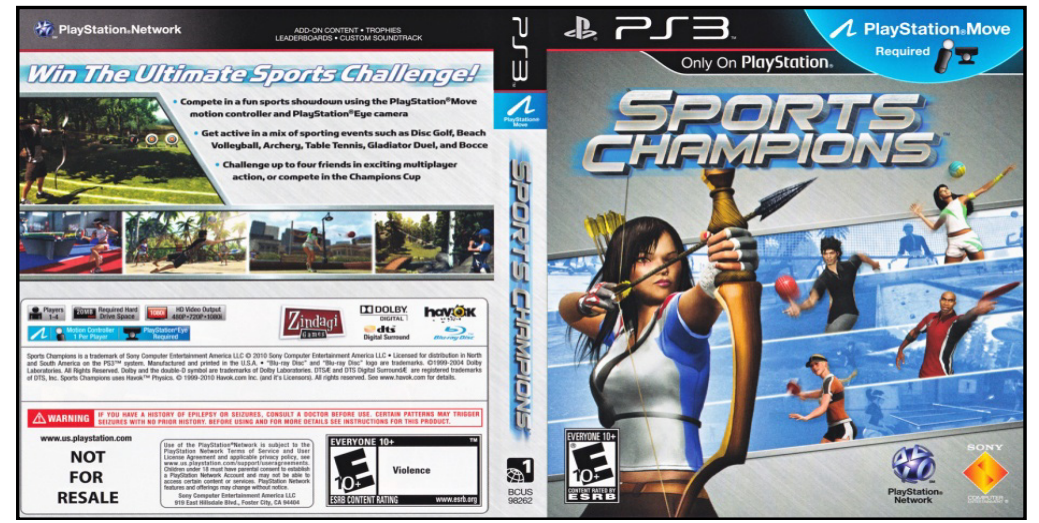

Figure 1. Sony Sports Champions front and back cover (Sony Computer Entertainment America LLC., 2010).

The game was selected because it offered the perfect playing scenarios, a purely competitive scenario and purely cooperative scenario, to evaluate which type of play participants prefer. In the competitive scenario, players compete against each other. The player who accumulates the most points wins. In the cooperative scenario, two players form a team and play against two computer avatars. The team to score the most points wins. Additional details about the two game scenarios are available in Appendix E. Furthermore, the nature of the game permitted conversation between participants to discuss strategies for winning in both scenarios. Thus, the game suited the purposes of the experiment well because it was ideal for collecting naturalistic behaviours.

In order to explore personality in a natural setting, the study was presented as a usability test. All participants played the game in pairs. They were either asked to bring a friend along or if they registered individually, they were asked if they would mind playing with a stranger.

Those who disagreed were thanked for their interest and explained that in order for the 
experiment to work, it is necessary to have two players playing together at the same time. Those who agreed were paired with another individual participant.

\section{Participants}

Students were recruited from the Carleton community by posters (Appendix B) and email notices (Appendix C). Posters were posted around campus message boards and e-mail notices were sent to Professors who taught introduction to Psychology, Sociology and Neuroscience courses asking if they could announce the study to their class. Participants had to be in good health and no history of epilepsy. Sixty-two participants (32 males, 30 females; 31 pairs) ranging in age from 18-57 years old ( $M=27$ years, $S D=8$ years) volunteered to participate in the study. On a scale from 1 to 10, approximately half of the participants rated themselves as experts while the other half novices with regard to their video gaming experience $(M=5.1, S D=2.7)$, most of them have not played the game before ( 11 have, 51 have not $)$, and twenty-one pairs knew each other, but the remainder did not. Participants completed a personality test (Appendix D, Part C) by Simmons, Wehner, Tucker, and King (1988) to evaluate their competitiveness and cooperativeness and Table 2 shows a breakdown of gender pairings with respect to personality pairings. The scale used for measuring motivation to favour cooperative or competitive strategies for success developed by Simmons, et al. (1988) has been shown to be non sex or age biased and the entire scale yields fair statistical reliability $(r=0.78)$.

Table 2

Gender pairings with respect to personality pairings

\begin{tabular}{lcccc}
\hline & \multicolumn{3}{c}{ Personality Pairings } & \\
\cline { 2 - 5 } Gender Pairings & $\begin{array}{c}\text { Competitive vs. } \\
\text { Competitive }\end{array}$ & $\begin{array}{c}\text { Cooperative vs. } \\
\text { Cooperative }\end{array}$ & $\begin{array}{c}\text { Competitive vs. } \\
\text { Cooperative }\end{array}$ & Total \\
\hline Male vs. Male & 1 & 2 & 6 & 9 \\
Female vs. Female & 2 & 4 & 2 & 8 \\
Male vs. Female & 4 & 1 & 9 & 14 \\
\hline Total & 7 & 7 & 17 & 31 \\
\hline
\end{tabular}

\section{Design}

A 2 by 3 (game scenario: competitive and cooperative by personality pairings: competitive vs. competitive; cooperative vs. cooperative; competitive vs. cooperative) withinparticipant design was used. Table 3 shows the number of participant pairs who played in each game scenario with respect to personality pairings. 
Table 3

Number of participant pairs who played in each game scenario with respect to personality pairings

\begin{tabular}{lccc}
\hline & \multicolumn{3}{c}{ Personality Pairings } \\
\cline { 2 - 4 } Game Scenarios & $\begin{array}{c}\text { Competitive vs. } \\
\text { Competitive }\end{array}$ & $\begin{array}{c}\text { Cooperative vs. } \\
\text { Cooperative }\end{array}$ & $\begin{array}{c}\text { Competitive vs. } \\
\text { Cooperative }\end{array}$ \\
\hline Competitive & 7 & 7 & 17 \\
Cooperative & 7 & 7 & 17 \\
\hline
\end{tabular}

Conditions were counterbalanced across participant pairs such that half played in the competitive scenario first followed by the cooperative scenario. This order was reversed for the other half of participant pairs.

\section{Apparatus}

In a closed laboratory setting, Bocce was displayed using a 1080p multimedia projector onto a white wall. The Sony Playstation 3 (PS3) played the disc and a PS3eye camera detected the participant's actions by sensing the position of the MoveMotion Controller. A separate set of multimedia speakers were attached to the projector for producing better sound. A video camcorder was used to record behaviours of participants and wireless heart rate monitors collected heart rate data. Figure 2 shows how the equipment was setup. Figure 3 is a schematic providing measurements for screen size and location of each apparatus. Table 4 lists all of the equipment that was used in the experiment, an image of the actual hardware, the model number, some general specifications, and web links for where further information regarding each apparatus may be found.

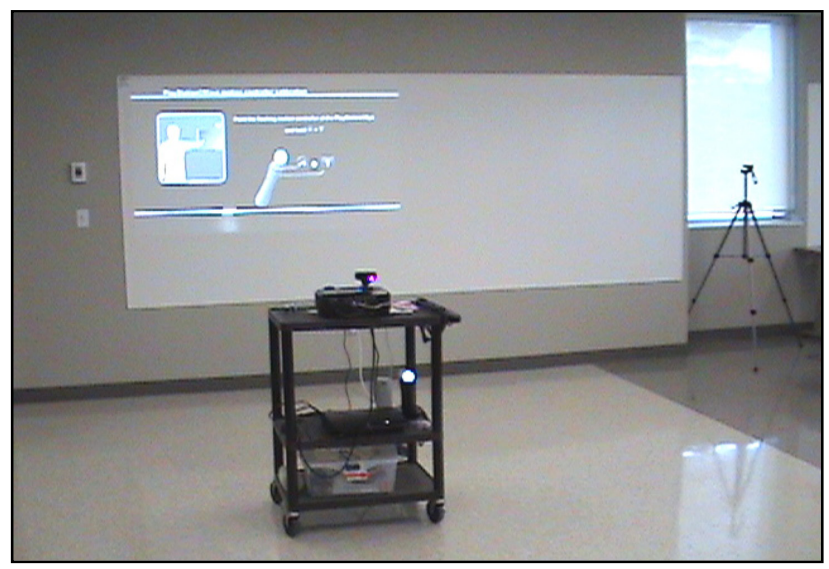

Figure 2. Photo of equipment setup 


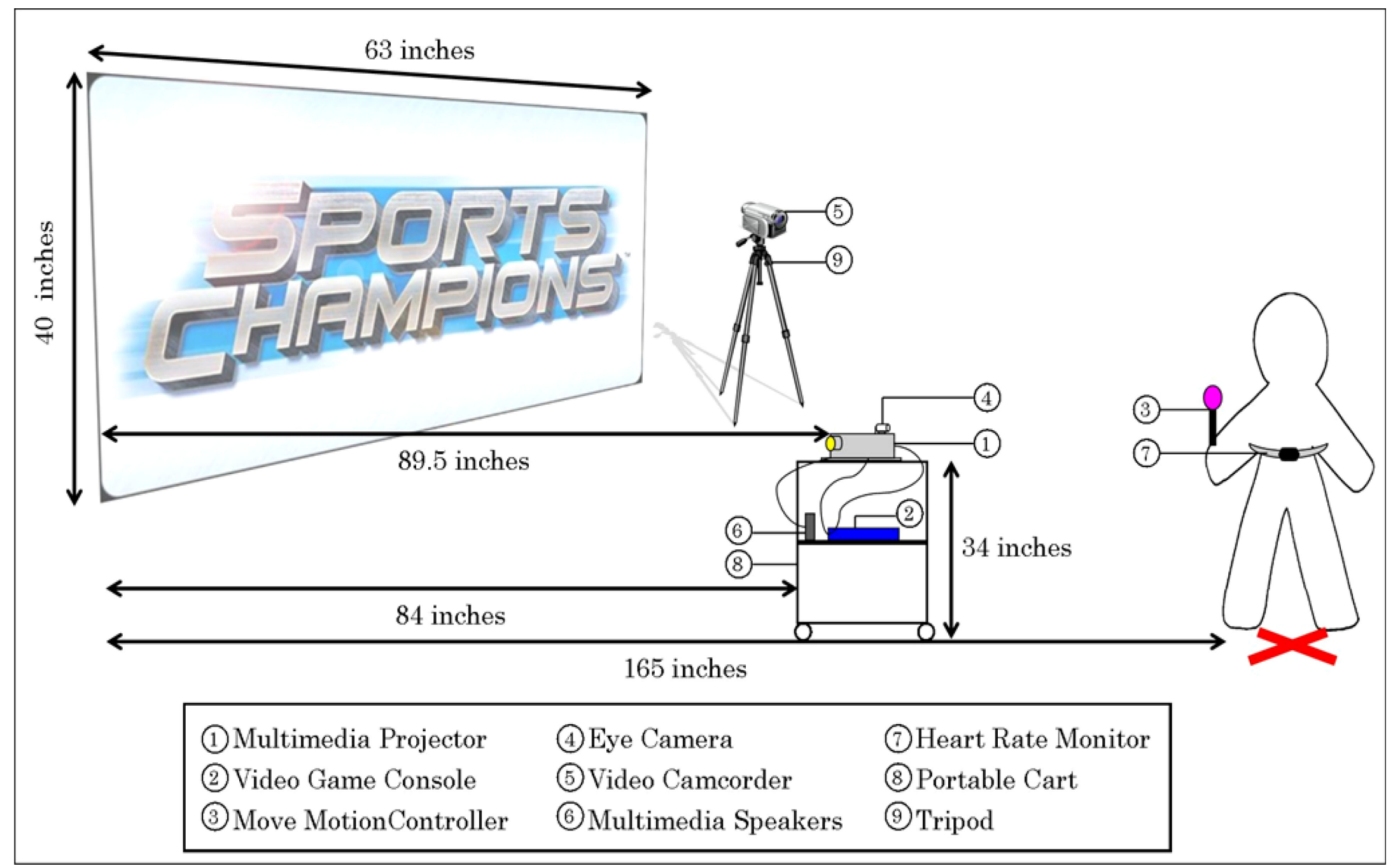

Figure 3. Schematic of experimental setup 
Table 4.

Equipment information and specifications

\begin{tabular}{|c|c|c|c|c|}
\hline Equipment & Manufacturer & Model No. & General Specifications & Web Link \\
\hline Multimedia Projector & ViewSonic & PJD6531w & 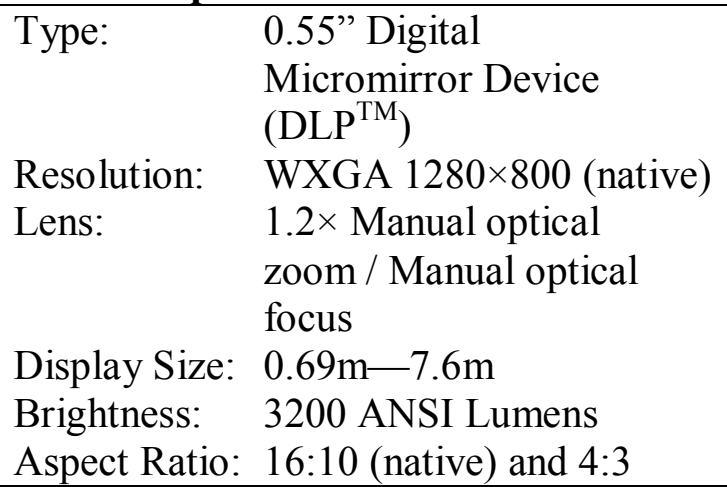 & $\begin{array}{l}\frac{\text { http://www1.viewsonic.com }}{\text { /products/projectors/pjd653 }} \\
\underline{1 \mathrm{w} . \mathrm{htm}}\end{array}$ \\
\hline Video Game Console & SONY & $\begin{array}{l}\text { PlayStation3 } \\
\text { CECH-2101a } \\
4^{\text {th }} \text { generation } \\
\text { Released } \\
\text { March, } 2010\end{array}$ & $\begin{array}{ll}\text { GPU Process: } & 65 \mathrm{~nm} \\
\text { CPU Process: } & 45 \mathrm{~nm} \\
\text { Front USB: } & 2 \\
\text { Power: } & 250 \mathrm{~W} \\
\text { HD Capacity: } & 120 \mathrm{~GB} \\
\text { Regions: } & 00010304050712 \\
& (J P, N A, \text { EU/PAL) }\end{array}$ & http://us.playstation.com/ \\
\hline Move MotionController & SONY & 99022 & $\begin{array}{ll}\text { Power: Lithium-ion Battery } \\
\text { Input: } \quad \text { Motion sensing: } \\
& \text { 3-axis accelerometer, 3-axis } \\
& \text { angular rate sensor } \\
& \text { - } \quad \text { Location tracking: } \\
& \text { magnetometer, object } \\
& \text { recognition (via PlayStation } \\
& \text { Eye or PlayStation Camera) } \\
-\quad & 1 \text { Analog trigger: T } \\
-\quad & 8 \text { Buttons: } \triangle, \circ, \times, \square, \text { Start, } \\
& \text { Select, Home, Move } \\
\text { Connectivity: Bluetooth, USB }\end{array}$ & $\begin{array}{l}\underline{\mathrm{http}: / / \text { us.playstation.com/ps }} \\
\underline{\text { 3/accessories/playstation- }} \\
\underline{\text { move-motion-controller- }} \\
\underline{\text { ps3.html }}\end{array}$ \\
\hline
\end{tabular}




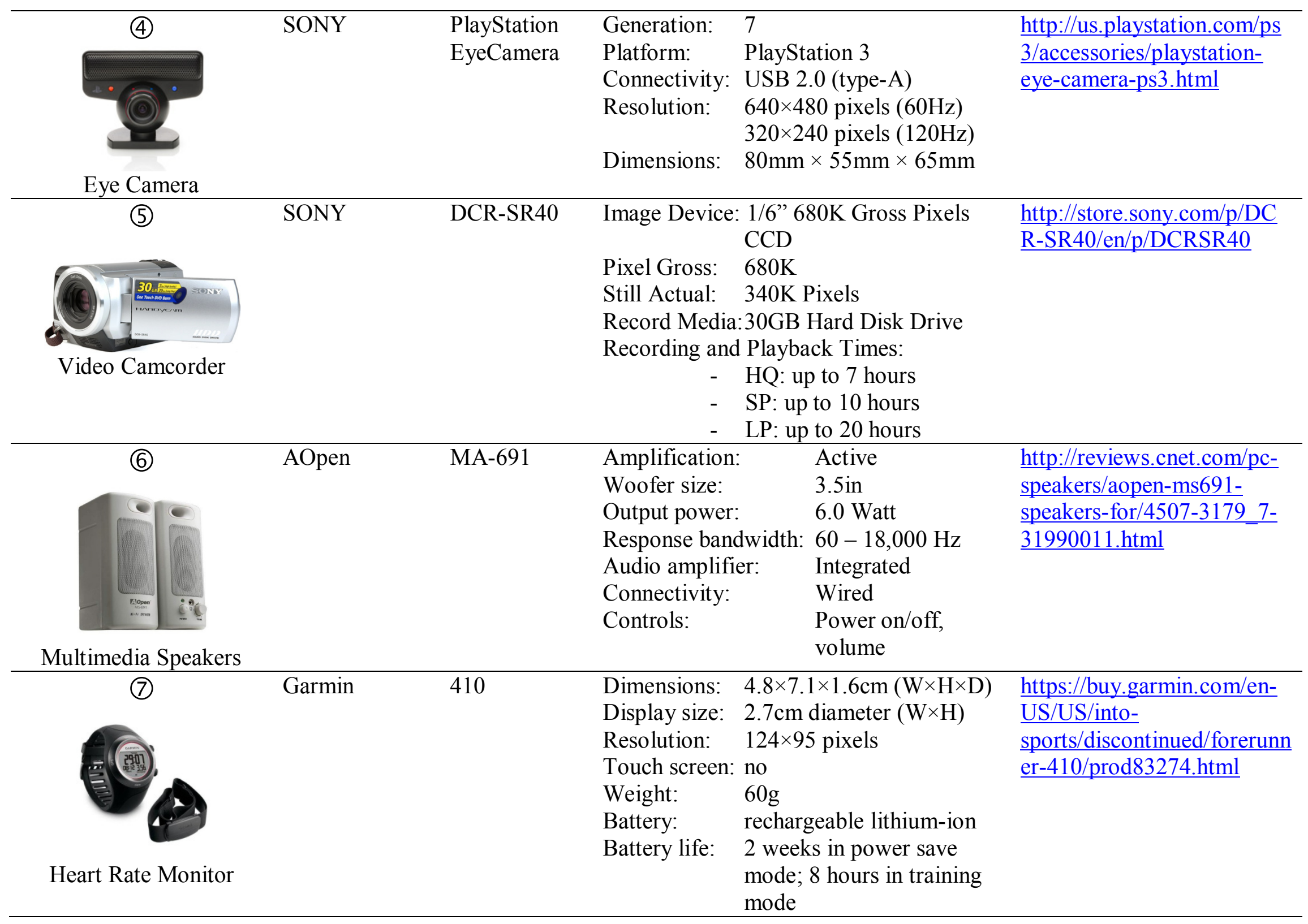


Comparing Personality Types in a Video Game Context 19

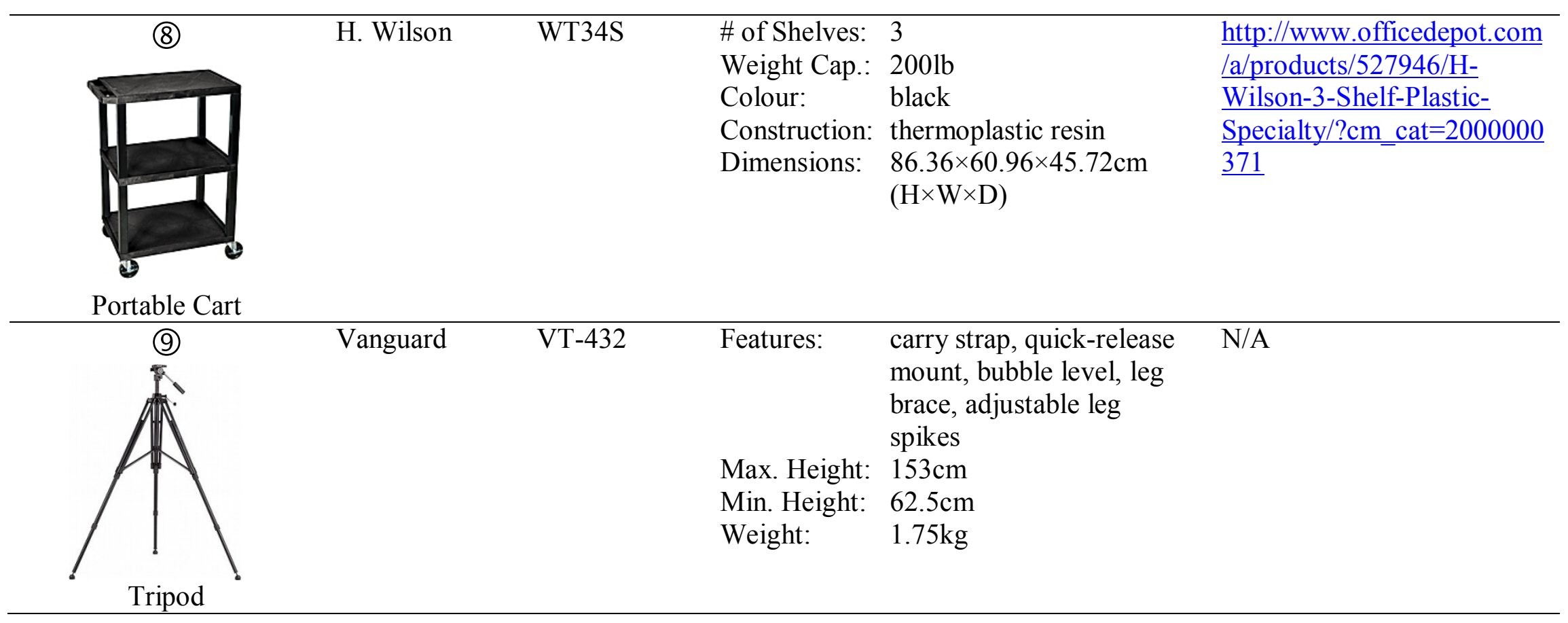




\section{Materials}

The materials used in this experiment included two consent forms - one before the experiment (Appendix E), and one after (Appendix G), debriefing form (Appendix H), postgame questionnaire (Appendix D), and an observations record sheet (Appendix I). The preexperiment consent form provided some general details about the study and explained what participants will be asked to do; whereas the post-experiment consent form revealed the true purpose of the study and asked for permission to use the collected data. The debriefing form reiterated the actual goal of the study and listed contact information if participants should have any further questions regarding the study. The observations record sheet was used to make note of any interesting actions between participants during the game. Lastly, the post-game questionnaire collected demographical information and consisted questions which evaluated the game they played, their perception of the other participant, and whether or not the participant enjoyed playing with another person. Table 5 below provides the rationale for all questions in the post-game questionnaire.

Table 5

Rationale for questions in post-game questionnaire (Appendix D)

\begin{tabular}{|c|c|c|}
\hline Part & Question \# & Rationale \\
\hline A & $1-7$ & To collect demographical information. \\
\hline \multirow[t]{5}{*}{ B } & $2 \& 3,6 \& 7$ & $\begin{array}{l}\text { To detect which game scenario the participant enjoyed playing in } \\
\text { most. }\end{array}$ \\
\hline & $8-11$ & To detect the participant's perception of the other player. \\
\hline & $12-14$ & To detect how influential the other player was on the participant. \\
\hline & $4 \& 5,15-17$ & $\begin{array}{l}\text { To determine if the participant enjoyed playing with another person } \\
\text { or not. }\end{array}$ \\
\hline & $1,18-23$ & To disguise the true purpose of the experiment. \\
\hline $\mathrm{C}$ & $1-24$ & To detect participant's personality type - competitive/cooperative. \\
\hline
\end{tabular}

\section{Procedures}

The study was approximately 1 hour and was separated in three parts - a practice session, followed by two experimental sessions. The script used to conduct the experiment is available in Appendix J. 
First, participants were informed that they were taking part in a usability study to evaluate the PS3. After signing an informed consent form (Appendix F), participants were introduced to the rules of the game and shown how to use the MoveMotion Controller. In the practice session, participants learned about throwing, aiming, spinning the ball, and were told they may use the red " $x$ " (Figure 5) on the floor as a reference point for approximately where to stand to toss a ball. Then, participants were asked if they would mind wearing a heart rate monitor. Those who refused to wear one, the experiment carried on without it. The experimenter explained that the heart rate monitor needs to go underneath clothing and strapped around the chest. Participants were directed to the nearest washrooms so they may strap it around themselves. When participants returned to the lab, they wore a wrist watch which was wirelessly connected to the heart rate monitor and the experimenter initiated the connection, as well as, the timer to begin collecting heart rate data. For hygienic reasons, heart rate monitors were sanitized with a piece of Lysol disinfectant towel (Reckitt Benckiser, 2010) before and after use. If data was lost, it was excluded from the dataset.

Before beginning the game, participants were arbitrarily assigned a player number (player 1, player 2) and told there were two types of playing scenarios - one of them is "head-to-head" and the other is "same team" - and will have the opportunity to try both. Furthermore, in each playing scenario, there are a total of eight rounds, but participants did not have to complete all of them. In each round, each player has four tries. After each round, if participants decided to continue, they would click next; if they decided to stop, the experimenter initiated the other scenario. To avoid any possible effects of the location, level of difficulty, or avatar, all participants played in the same court location (see Figure A3), same level of difficulty - silver, and were assigned the same avatar which matched their gender in both scenarios. Further details about the avatars are available in Appendix K. After a calibration procedure, participants began the game. Once participants were through with session one, they were offered a break and then session two followed.

During play, qualitative observations were noted by the experimenter using an observations record sheet (Appendix I). In addition, all sessions were video-recorded and heart rate measures were obtained. Those who refused to be video recorded, the experiment continued without it. From the video recordings, friendly and unfriendly facial expressions, gestures and 
language were collected for analysis. Table 6 shows the kinds of facial expressions, gestures and language that were gathered and some examples of each. As an objective measure, playing time and the number of rounds for each game scenario were recorded. If more time was spent in one game scenario compared to the other, it could be an indication of more enjoyment in that one specific game scenario. Similarly, if participants played more rounds in a particular game scenario, it would indicate that they could have enjoyed that particular game scenario more than the other.

Table 6

Example measures of expressions

\begin{tabular}{|c|c|c|}
\hline Measure & Expressions & Example \\
\hline \multirow[t]{4}{*}{ Facial expressions } & Happiness & - $\quad$ Smile / laughter \\
\hline & & - Excitement \\
\hline & Frustration & - Disappointment /grimace \\
\hline & & - $\quad$ Look down \\
\hline \multirow[t]{5}{*}{ Gestures } & Supportive & - $\quad$ Pat on the back \\
\hline & & - $\quad$ Firm hand shake after the game \\
\hline & & - $\quad$ Thumbs up \\
\hline & & - $\quad$ High five \\
\hline & Unsupportive & - $\quad$ Avoidance / turn away \\
\hline \multirow[t]{3}{*}{ Language } & Encouraging & - $\quad$ Good game \\
\hline & & - $\quad$ Let's play again \\
\hline & Discouraging & Sigh \\
\hline
\end{tabular}

After the game, participants completed a post-game questionnaire (Appendix D) to evaluate their playing experience and personality type. To ensure honesty and discourage interaction, participant pairs were physically separated while completing the questionnaire. And finally, participants were debriefed, informed of deceptions and asked to authorize use of the collected data. 
Comparing Personality Types in a Video Game Context 23

\section{Data Analysis and Results}

To investigate the effects of combining matched (competitive vs. competitive and cooperative vs. cooperative) and mismatched (competitive vs. cooperative) personality pairings with respect to enjoyment, both subjective and objective measures, as well as, qualitative observations will be presented in this section. Analysis of subjective measures comes from results collected in the post-game questionnaire (Appendix D) while objective measures include analysis of two variables - time and number of rounds. As for results from qualitative observations, behaviours of participant pairs during play were gathered from video recordings.

\section{Personality Type}

Prior to analyzing any data, personality type (competitive or cooperative) of each individual participant was determined. To categorize participants as either competitive or cooperative, a median split procedure was conducted on the mean scores of all competitive questions and cooperative questions collected in a personality questionnaire (Appendix D, Part C). The median split procedure was used because it permitted the analysis of two group differences instead of individual differences (MacCallum, Zhang, Preacher, \& Rucker, 2002). However, drawbacks associated with the use of a median split include: loss of information regarding individual differences, effect size, power, and measurement reliability (MacCallum, et al., 2002). A 1 to 5 point Likert scale $(1=$ always, $2=$ usually, $3=$ sometimes, $4=$ rarely, $5=$ never) was used to evaluate the level of agreement on competitive and cooperative questions. Those who scored below the median for competitive (Median Competitive $_{2.36}$ ) questions were identified as competitive individuals. Those who scored below the median for cooperative $\left(\right.$ Median $\left._{\text {Cooperative }}=2.00\right)$ questions were identified as cooperative individuals. Those who scored above or below on both personality type medians, a tie breaker formula was devised:

Tie Breaker $=\mid$ Mean $_{\text {Competitive }}-$ Median $_{\text {Competitive }}|<|$ Mean $_{\text {Cooperative }}-$ Median $_{\text {Cooperative }} \mid$

The tie breaker formula separated individual scores by comparing the individual's competitive and cooperative mean score against the competitive and cooperative median score and the value closer to the median score determined their personality type. For example: Median Competitive $=2.36$, and Median Cooperative $=2.00$, if Mean Competitive $=2.27$, and Mean Cooperative $=1.75$, 2.27 is "closer to" 2.36 whereas 1.75 is further away from 2.00 , and so this particular participant 
was identified competitive. As a result, 31 participants were identified as competitive while the other 31, cooperative. Figure 4 below shows the distributions of personality type for each gender. As seen in the histograms, male participants scored slightly lower on both personality traits compared to females, and this is supported by the descriptive statistics as presented in Table 7.

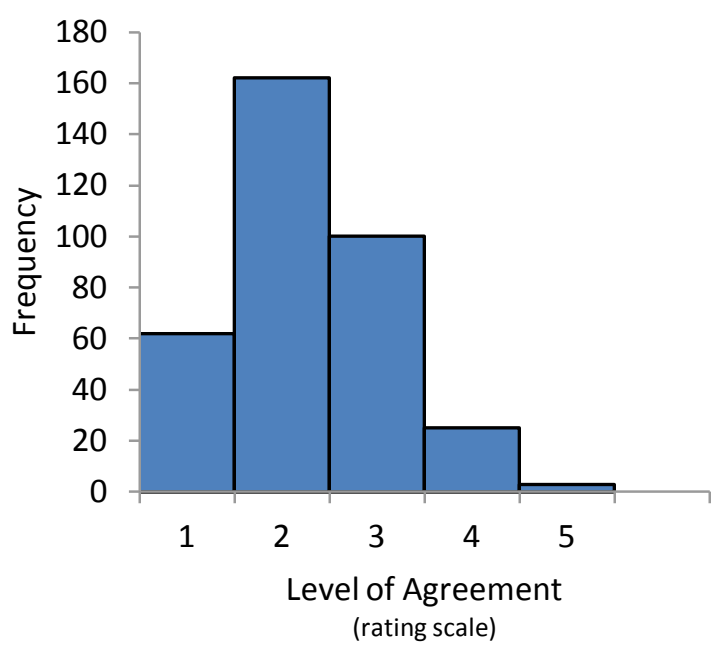

a. Males Competitive

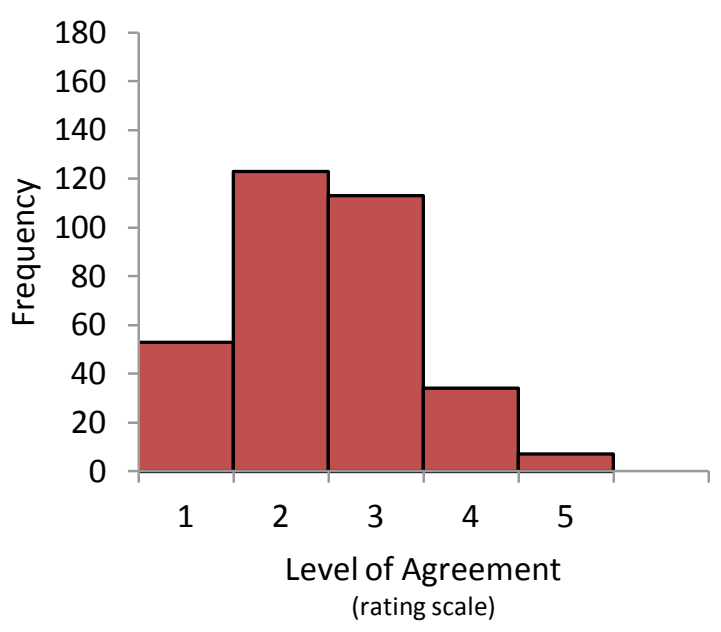

c. Females Competitive

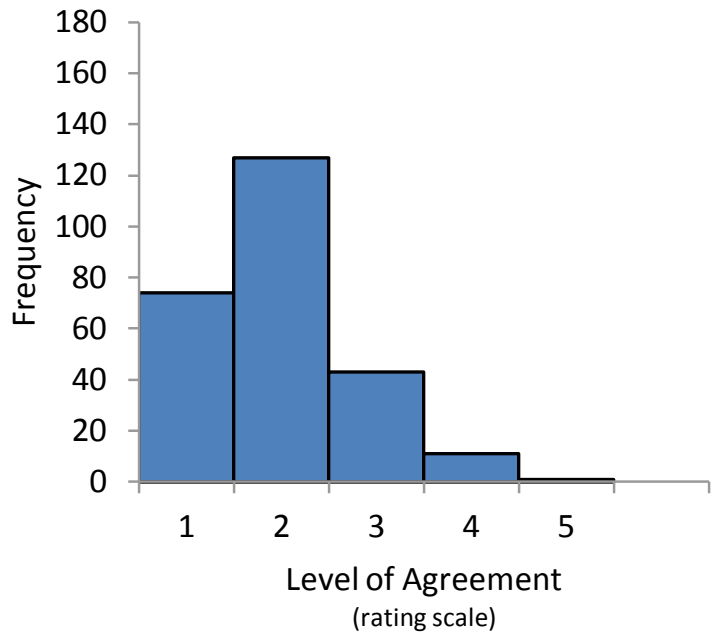

b. Males Cooperative

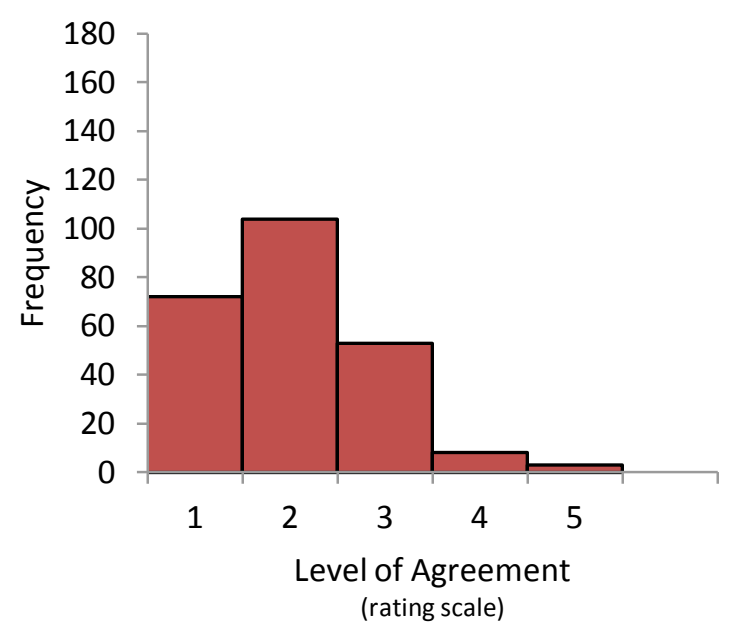

d. Females Cooperative

Figure 4. Distributions of agreement level on a 5 point Likert scale $(1=$ never to $5=$ always $)$ for personality type with respect to gender. 
Table 7

Descriptive statistics for gender with respect to personality type

\begin{tabular}{|c|c|c|c|c|c|c|c|c|}
\hline \multirow[b]{3}{*}{ Personality Type } & \multicolumn{8}{|c|}{ Gender } \\
\hline & \multicolumn{4}{|c|}{ Male } & \multicolumn{4}{|c|}{ Female } \\
\hline & $M$ & $S D$ & Skewness & Kurtosis & $M$ & $S D$ & Skewness & Kurtosis \\
\hline Competitive & 2.28 & 0.86 & 0.42 & -0.02 & 2.45 & 0.95 & 0.31 & -0.23 \\
\hline Cooperative & 1.98 & 0.82 & 0.70 & 0.42 & 2.03 & 0.88 & 0.70 & 0.47 \\
\hline
\end{tabular}

Personality pairings were formulated after the experiment by combining the personality scores of two individual participants together. Three different possible personality pairings - a "competitive match" - competitive vs. competitive, "cooperative match" - cooperative vs. cooperative, and "mismatch" - competitive vs. cooperative resulted and Table 8 below shows how many participant pairs fell under each personality pairing category.

Table 8

Number of personality pairings in three different categories Personality Pairing Categories

\begin{tabular}{ccc}
\hline Competitive Match & Cooperative Match & Mismatch \\
\hline 7 & 7 & 17 \\
\hline
\end{tabular}

\section{Subjective Measures}

Part B of the post-game questionnaire (Appendix D) with a 1 to 7 point Likert scale (ranging from $1=$ strongly disagree to $7=$ strongly agree) were intended to evaluate game scenario enjoyment, the perception, as well as, influence of one participant on another, and whether or not a participant enjoyed playing with another person (Table 5). First, histograms (Appendix L) of frequency distributions and descriptive statistics (Table 9) for questions 2 to 17 (Part B) in the post-game questionnaire (Appendix D) were generated to examine the normality of the sample. Based on the skewness of the distributions (Appendix L), and kurtosis values (Table 9), non-parametric tests were selected for analysis. An alpha level of 0.05 was used for all statistical tests. 
Table 9

Descriptive statistics for the level of agreement with respect to questions 2-17 (Part B) in the post-game questionnaire (Appendix D)

\begin{tabular}{|c|c|c|c|c|c|c|}
\hline \# & Post Game Questionnaire Statements & Mean & $S D$ & Median & Skewness & Kurtosis \\
\hline 2 & I liked playing on the same team. & 5.47 & 1.33 & 6.00 & -1.45 & 2.11 \\
\hline 3 & I liked playing head-to-head. & 5.56 & 1.35 & 6.00 & -1.30 & 1.03 \\
\hline 4 & I enjoyed playing with another player. & 6.34 & 0.75 & 6.00 & -1.63 & 5.22 \\
\hline 5 & $\begin{array}{l}\text { I thought that playing with another } \\
\text { player was fun. }\end{array}$ & 6.37 & 0.71 & 6.00 & -1.83 & 7.08 \\
\hline 6 & $\begin{array}{l}\text { I enjoyed playing against another } \\
\text { player. }\end{array}$ & 5.63 & 1.42 & 6.00 & -1.27 & 0.99 \\
\hline 7 & $\begin{array}{l}\text { I thought that playing against another } \\
\text { player was boring. }\end{array}$ & 2.18 & 1.39 & 2.00 & 1.93 & 3.99 \\
\hline 8 & $\begin{array}{l}\text { I felt my partner was helpful when we } \\
\text { were playing against the computer. }\end{array}$ & 5.50 & 1.24 & 6.00 & -0.88 & 0.60 \\
\hline 9 & $\begin{array}{l}\text { I felt my partner made more mistakes } \\
\text { than I did. }\end{array}$ & 3.35 & 1.70 & 4.00 & 0.39 & -1.03 \\
\hline 10 & $\begin{array}{l}\text { I felt my partner was a burden to me in } \\
\text { the game. }\end{array}$ & 2.24 & 1.30 & 2.00 & 1.24 & 1.07 \\
\hline 11 & $\begin{array}{l}\text { I felt the other player was a good } \\
\text { competitor. }\end{array}$ & 5.69 & 1.11 & 6.00 & -1.66 & 3.20 \\
\hline 12 & $\begin{array}{l}\text { I would pick the same person if I was } \\
\text { playing a champion game. }\end{array}$ & 5.08 & 1.53 & 6.00 & -0.77 & -0.22 \\
\hline 13 & $\begin{array}{l}\text { I felt pressured to win because of the } \\
\text { other player. }\end{array}$ & 3.50 & 1.92 & 3.00 & 0.36 & -1.21 \\
\hline 14 & $\begin{array}{l}\text { I was motivated to play better because } \\
\text { of the other player. }\end{array}$ & 5.27 & 1.33 & 6.00 & -1.04 & 0.88 \\
\hline 15 & $\begin{array}{l}\text { I would like to play with this person } \\
\text { again. }\end{array}$ & 5.94 & 0.77 & 6.00 & -0.57 & 0.39 \\
\hline 16 & I could have played better on my own. & 3.16 & 1.51 & 3.00 & 0.70 & 0.02 \\
\hline 17 & I would have rather played alone. & 1.89 & 1.04 & 2.00 & 2.21 & 8.40 \\
\hline
\end{tabular}

Before conducting any analyses on participant pairs, a median test was conducted on each individual participant's personality type with respect to questions 2 to 17 (Part B) in the postgame questionnaire (Appendix D) to investigate if there are any individual differences with respect to both game scenarios. Table 10 below provides all the results that were statistically significant. 
Table 10

Statistically significant median test results for individual personality types with respect to level of agreement evaluated by part B in the post-game questionnaire (Appendix D)

\begin{tabular}{|c|c|c|c|c|c|c|c|}
\hline \multirow[b]{3}{*}{ \# } & \multirow{3}{*}{$\begin{array}{l}\text { Post-Game Questionnaire } \\
\text { Statements }\end{array}$} & \multicolumn{4}{|c|}{ Personality Type } & \multirow[b]{3}{*}{$x^{2}$} & \multirow[b]{3}{*}{$p$} \\
\hline & & \multicolumn{2}{|c|}{ Competitive } & \multicolumn{2}{|c|}{ Cooperative } & & \\
\hline & & Above & Below & Above & Below & & \\
\hline 2 & $\begin{array}{l}\text { I liked playing on the same } \\
\text { team. }\end{array}$ & 2 & 29 & 8 & 23 & 4.29 & 0.04 \\
\hline 4 & $\begin{array}{l}\text { I enjoyed playing with } \\
\text { another player. }\end{array}$ & 10 & 21 & 18 & 13 & 4.17 & 0.04 \\
\hline 5 & $\begin{array}{l}\text { I thought that playing with } \\
\text { another player was fun. }\end{array}$ & 10 & 21 & 18 & 13 & 4.17 & 0.04 \\
\hline 8 & $\begin{array}{l}\text { I felt my partner was helpful } \\
\text { when we were playing } \\
\text { against the computer. }\end{array}$ & 1 & 30 & 12 & 19 & 11.78 & 0.00 \\
\hline 12 & $\begin{array}{l}\text { I would pick the same } \\
\text { person if I was playing a } \\
\text { champion game. }\end{array}$ & 1 & 30 & 8 & 23 & 6.37 & 0.01 \\
\hline
\end{tabular}

Note. "Above" = the number of participants who scored above or equal to the median. "Below" $=$ the number of participants who scored below the median.

From table 10, results seem to suggest that both competitive and cooperative individuals do not enjoy playing in a cooperative game scenario as evaluated by question 2 . From questions 4 and 5, results suggest that competitive individuals did not enjoy playing with another player, as much as, cooperative individuals. Moreover, results of questions 8 and 12 suggest that competitive individuals felt their partner was unhelpful in a cooperative game scenario and would not select the same partner in a champion game. On the other hand, cooperative individuals felt a similar way, however, less so than competitive individuals.

Effect of Personality Pairing. It was hypothesized that both competitive matched and cooperative matched personality pairings would enjoy playing together while mismatched pairings would not. To examine effects of personality pairings, an intra-class correlation was conducted on questions 2 to 17 (Part B) in the post-game questionnaire (Appendix D) with respect to both types of matched and mismatched personality pairings. Results showed that matched personality pairings particularly enjoyed playing in a competitive scenario, $\mathrm{ICC}=$ 0.843, and regardless whether personality pairings were matched or mismatched, participants enjoyed playing with another person, $\mathrm{ICC}=0.678$. Additionally, a Kruskal Wallis test was used 
to examine if there were any effects of matched and mismatched personality pairings with respect to questions 2 to 17 (Part B) in the post-game questionnaire. Table 11 below provides results that were statistically significant.

Table 11

Statistically significant Kruskal Wallis test results for personality pairings with respect to level of agreement evaluated by part B in the post-game questionnaire (Appendix D)

\begin{tabular}{|c|c|c|c|c|c|c|}
\hline \multirow[b]{2}{*}{ \# } & \multirow[b]{2}{*}{$\begin{array}{l}\text { Post-Game Questionnaire } \\
\text { Statements }\end{array}$} & \multicolumn{3}{|c|}{ Mean Rank } & \multirow[b]{2}{*}{$H$} & \multirow[b]{2}{*}{$P$} \\
\hline & & $\begin{array}{c}\text { Competitive } \\
\text { Match } \\
\end{array}$ & $\begin{array}{c}\text { Cooperative } \\
\text { Match } \\
\end{array}$ & Mismatch & & \\
\hline 4 & $\begin{array}{l}\text { I enjoyed playing with } \\
\text { another player. }\end{array}$ & $\begin{array}{c}23.25 \\
(N=14)\end{array}$ & $\begin{array}{c}40.36 \\
(N=14)\end{array}$ & $\begin{array}{c}31.25 \\
(N=34)\end{array}$ & 7.83 & 0.02 \\
\hline 8 & $\begin{array}{l}\text { I felt my partner was helpful } \\
\text { when we were playing } \\
\text { against the computer. }\end{array}$ & $\begin{array}{c}29.43 \\
(N=14)\end{array}$ & $\begin{array}{c}44.07 \\
(N=14)\end{array}$ & $\begin{array}{c}27.18 \\
(N=34)\end{array}$ & 9.65 & 0.01 \\
\hline 17 & $\begin{array}{l}\text { I would have rather played } \\
\text { alone. }\end{array}$ & $\begin{array}{c}41.39 \\
(N=14)\end{array}$ & $\begin{array}{c}26.54 \\
(N=14)\end{array}$ & $\begin{array}{c}29.47 \\
(N=34)\end{array}$ & 6.58 & 0.04 \\
\hline
\end{tabular}

Results presented in Table 11 seem to suggest that in a cooperative match personality pairing situation, participant pairs particularly enjoyed playing with each other (question 4) and found their partner helpful while the both of them were playing against the CPU avatars (question 8) compared to participant pairs who were in a competitive and mismatched personality pairing situation. Additionally, results of question 17 suggest that in a competitive match personality pairing situation, participants expressed more preference for playing independently compared to those who were in a cooperative and mismatched personality pairing situation.

Effect of Gender. To determine if there was an effect of gender on participants individually, a Mann-Whitney $U$ test was conducted on questions 2 to 17 (Part B) in the postgame questionnaire (Appendix D). Table 12 below provides results that were statistically significant. 
Table 12

Statistically significant Mann-Whitney $U$ test results for gender differences with respect to level of agreement evaluated by part B in the post-game questionnaire (Appendix D)

\begin{tabular}{|c|c|c|c|c|c|}
\hline \multirow[b]{2}{*}{ \# } & \multirow[b]{2}{*}{ Post-Game Questionnaire Statements } & \multicolumn{2}{|c|}{ Mean Rank } & \multirow[b]{2}{*}{$U$} & \multirow[b]{2}{*}{$P$} \\
\hline & & Male & Female & & \\
\hline 10 & $\begin{array}{l}\text { I felt my partner was a burden to me in } \\
\text { the game. }\end{array}$ & 38.86 & 23.65 & 244.50 & 0.00 \\
\hline 12 & $\begin{array}{l}\text { I would pick the same person if I was } \\
\text { playing a champion game. }\end{array}$ & 25.64 & 37.75 & 292.50 & 0.01 \\
\hline 16 & I could have played better on my own. & 35.91 & 26.80 & 339.00 & 0.01 \\
\hline 17 & I would have rather played alone. & 36.92 & 25.72 & 306.50 & 0.01 \\
\hline
\end{tabular}

Results in Table 12 suggest that males felt that the other player hindered their performance during the game (question 10), they could have performed better on their own (question 12), and they would have rather played alone (question 17) compared to females. In contrast, results of question 12 suggest that in a champion game, females would be more likely to select the same player (both to compete against and play together with) compared to males. Next, to examine if there was an effect of gender pairings (males vs. male, females vs. females and males vs. females), a Kruskal Wallis test was conducted on questions 2 to 17 (Part B) in the postgame questionnaire (Appendix D). Results showed that male pairings in particular enjoyed playing in a competitive game scenario as presented in Table 13 below.

Table 13

Statistically significant Kruskal Wallis test results for gender pairings with respect to level of agreement evaluated by part B in the post-game questionnaire (Appendix D)

\begin{tabular}{llccccc} 
& & \multicolumn{3}{c}{ Mean Rank } & & \\
\cline { 2 - 4 } Post-Game Questionnaire & Statements & Male vs. & Female vs. & Male vs. & & \\
& & Male & Female & Female & $H$ & $P$ \\
\hline \multirow{2}{*}{3} & I liked playing head-to-head. & 36.22 & 19.66 & 35.23 & 10.67 & 0.01 \\
& $(N=18)$ & $(N=16)$ & $(N=28)$ & & \\
\multirow{2}{*}{6} & $\begin{array}{l}\text { I enjoyed playing against } \\
\text { another player. }\end{array}$ & 37.94 & 21.06 & 33.32 & 8.69 & 0.01 \\
\hline
\end{tabular}


Effect of Relationship. To determine if there was an effect of relationship (friend vs. stranger) a Mann-Whitney $U$ test was conducted on relationship with respect to the question that asked whether or not the participant would like to play with the same person again in the postgame questionnaire. Results showed that those who knew each other reported slightly more preference with respect to the question "I would like to play with this person again" than those who did not $(U=208, p=0.07)$, with a mean ranking of $33.34(N=50)$ for friends, and a mean ranking of $23.83(N=12)$ for strangers.

Furthermore, to examine of there was an effect of game scenario with respect to relationship (friend vs. stranger), separate statistical tests were conducted on two questions ("I liked playing head-to-head" and "I liked playing on the same team") that evaluated which of the two game scenarios the participant enjoyed playing in most in the post-game questionnaire (Appendix D). First, to examine if there was an effect of relationship in the competitive scenario with respect to the three personality pairings, a Mann-Whitney $U$ test was conducted on the question "I liked playing head-to-head". No significant differences were found as shown in Table 14 below. Next, to investigate if there was an effect of relationship in the cooperative scenario with respect to the three personality pairings, a Mann-Whitney $U$ test was conducted on the question "I liked playing on the same team". No significant differences were found as shown in Table 15 below.

Table 14

Mann-Whitney $U$ tests for relationship with respect to personality parings in the competitive game scenario

\begin{tabular}{|c|c|c|c|c|}
\hline \multirow[b]{2}{*}{ Personality Pairing } & \multicolumn{2}{|c|}{$N$} & \multirow[b]{2}{*}{$U$} & \multirow[b]{2}{*}{$P$} \\
\hline & Friend & Stranger & & \\
\hline Competitive Match & 10 & 4 & 12.00 & 0.22 \\
\hline Cooperative Match & 12 & 2 & 5.00 & 0.18 \\
\hline Mismatch & 28 & 6 & 79.50 & 0.82 \\
\hline
\end{tabular}


Table 15

Mann-Whitney $U$ tests for relationship with respect to personality parings in the cooperative game scenario

\begin{tabular}{|c|c|c|c|c|}
\hline \multirow[b]{2}{*}{ Personality Pairing } & \multicolumn{2}{|c|}{$N$} & \multirow[b]{2}{*}{$U$} & \multirow[b]{2}{*}{$P$} \\
\hline & Friend & Stranger & & \\
\hline Competitive Match & 10 & 4 & 11.00 & 0.17 \\
\hline Cooperative Match & 12 & 2 & 8.00 & 0.41 \\
\hline Mismatch & 28 & 6 & 64.00 & 0.34 \\
\hline
\end{tabular}

Effect of Game Experience. It was hypothesized those who have a great deal of experience in playing video games may have not enjoyed the game as much as those who had very little video game experience. To determine if there was an effect of game experience, game experience scores, evaluated by a 10 point Likert scale ranging from $1=$ novice to $10=$ expert, were divided into two experience groups (high vs. low) using a median split procedure. Twentynine participants scored above the median and thirty-three scored below the median; Median Game Experience $=5.00$. Then, a median test was conducted on questions 2 to 17 (Part B) in the post-game questionnaire (Appendix D). Marginally significant results are shown in Table 16 below.

Table 16

Marginally significant median test results for game experience with respect to level of agreement evaluated by part B in the post-game questionnaire (Appendix D)

\begin{tabular}{|c|c|c|c|c|c|c|c|}
\hline \multirow[b]{3}{*}{ \# } & \multirow{3}{*}{$\begin{array}{l}\text { Post Game Questionnaire } \\
\text { Statements }\end{array}$} & \multicolumn{4}{|c|}{ Game Experience } & \multirow[b]{3}{*}{$x^{2}$} & \multirow[b]{3}{*}{$p$} \\
\hline & & \multicolumn{2}{|c|}{ High } & \multicolumn{2}{|c|}{ Low } & & \\
\hline & & Above & Below & Above & Below & & \\
\hline 8 & $\begin{array}{l}\text { I felt my partner was helpful } \\
\text { when we were playing } \\
\text { against the computer. }\end{array}$ & 10 & 23 & 3 & 26 & 3.71 & 0.05 \\
\hline 11 & $\begin{array}{l}\text { I felt the other player was a } \\
\text { good competitor. }\end{array}$ & 8 & 25 & 2 & 27 & 3.43 & 0.06 \\
\hline 13 & $\begin{array}{l}\text { I felt pressured to win } \\
\text { because of the other player. }\end{array}$ & 12 & 21 & 17 & 12 & 3.07 & 0.08 \\
\hline
\end{tabular}

Note. "Above" = the number of participants who scored above or equal to the median. "Below" $=$ the number of participants who scored below the median. 
According to results presented in Table 16, regardless of game experience, individual participants found their partner unhelpful while the both of them were playing against the computer avatars as evaluated by question 8 . Likewise, both participants groups, whether high or low game experience, results of question 11 suggest that more participants felt the other player was not a good competitor. And finally, results of question 13 suggest that participants who had more game experience felt less pressure to win because of the other player whereas participants who had less game experience felt more pressure to win because of the other player.

So far, statistical tests that have been conducted in this section on questions 2 to 17 (Part B) in the post-game questionnaire, seem to suggest that matched personality pairings particularly enjoyed playing in a competitive scenario, and participants generally enjoyed playing with another person in both game scenarios. In addition, males especially enjoy playing in a competitive game scenario and friends enjoyed playing together more than strangers irrespective of scenario type.

\section{Objective Measures}

Two different types of objective measures (time, and number of rounds) were used to evaluate how much participant pairs enjoyed playing with each other in the two game scenarios: competitive and cooperative. "Time" is the length of time participants spent playing. A time was recorded for a competitive game scenario and another time was recorded for a cooperative game scenario. "Number of rounds" is the number of rounds players played in both competitive and cooperative game scenarios. The number of rounds was also recorded for each game scenario.

Time. Table 17 below shows the average time (in seconds) participants played in each game scenario with respect to the three personality pairings.

\section{Table 17}

Average times (in seconds) for game scenarios with respect to personality pairings

\begin{tabular}{lcccccc}
\hline & \multicolumn{5}{c}{ Personality Pairings } \\
\cline { 2 - 7 } Game Scenarios & \multicolumn{2}{c}{ Competitive Match } & \multicolumn{2}{c}{ Cooperative Match } & \multicolumn{2}{c}{ Mismatch } \\
\cline { 2 - 7 } Competitive & $M$ & $S D$ & $M$ & $S D$ & $M$ & $S D$ \\
Cooperative & 692 & 149 & 670 & 217 & 548 & 258 \\
& 487 & 230 & 493 & 163 & 530 & \multirow{2}{*}{189} \\
\hline
\end{tabular}


It was hypothesized that matched personality pairings would play for a longer period of time than mismatched pairings. It was also hypothesized that a competitive vs. competitive pairing would play longer in a competitive game scenario, than a cooperative game scenario; and a cooperative versus cooperative pairing would play longer in a cooperative game scenario than a competitive game scenario. A 2 (game scenario: competitive, cooperative) $\times 3$ (personality pairings: competitive vs. competitive, cooperative vs. cooperative and competitive vs. cooperative) mixed ANOVA showed a significant main effect of time with respect to game scenario, $F(1,23)=4.93, p=0.04$. Participant pairs played longer in the competitive scenario $(M$ $=614.04$ seconds, $S D=221.00$ seconds $)$ compared to the cooperative scenario $(M=515.81$ seconds, $S D=191.51)$. There was no significant interaction effect of time on personality pairing with respect to game scenario, $F(1,23)=1.61, p=0.22$.

Number of Rounds. Table 18 below shows the average number of rounds participants played in each game scenario with respect to the three personality pairings.

Table 18

Average number of rounds for game scenarios with respect to personality pairings Personality Pairings

\begin{tabular}{lcccccc}
\cline { 2 - 6 } Game Scenarios & \multicolumn{2}{c}{ Competitive Match } & \multicolumn{2}{c}{ Cooperative Match } & \multicolumn{2}{c}{ Mismatch } \\
\cline { 2 - 6 } & $M$ & $S D$ & $M$ & $S D$ & $M$ & $S D$ \\
\hline Competitive & 4.29 & 2.06 & 4.29 & 1.11 & 3.82 & 1.42 \\
Cooperative & 3.29 & 1.50 & 4.57 & 1.99 & 3.94 & 1.56 \\
\hline
\end{tabular}

It was hypothesized that matched personality pairings would play more rounds compared to mismatched pairings. It was also hypothesized that a competitive vs. competitive pairing would play more rounds in a competitive game scenario, than a cooperative game scenario; and a cooperative vs. cooperative pairing would play more rounds in a cooperative game scenario than a competitive game scenario. A 2 (game scenario: competitive and cooperative) $\times 3$ (personality pairing: competitive vs. competitive, cooperative vs. cooperative, competitive vs. cooperative) mixed ANOVA was not statistically significant, $F(1,28)=0.31, p=0.58$. 
From results presented in this section, participant pairs played a longer game in a competitive scenario than in a cooperative scenario suggesting that competitive play seems to be more enjoyable. However, personality pairings did not seem to play a role in more or less enjoyment with respect to playing time, or the number of rounds in either game scenario. Next, qualitative observations that showed signs of enjoyment and engagement will be reported.

\section{Qualitative Observations}

Video recordings (out of 31 participant pairs, 5 pairs declined video recording) were analyzed by extracting any interesting behaviours that indicated signs of enjoyment and engagement that were visible among participant pairs during play. Themes were formulated based on detection of behavioural patterns that reoccurred between participant pairs and participants reactions to the game. However, not all participants were as expressive compared to others - some were more expressive while others were less expressive. For example, in response to humour, some responded with a strong laugh while others showed a light giggle. This demonstrates that there are individual differences, and that there are varying levels of emotional expression.

Three major themes were extracted from observing the video recordings as an indication of enjoyment and engagement: reaction to avatar's animations, positive reciprocation, and reaction to winning. The first theme captures a participant's reactions to the avatar's actions. For example, before the game, the avatar would introduce themselves to the player by performing a brief pose, and a participant's reaction was laughter. Throughout the game, avatars produce various sounds and gestures such as laughter immediately after a good toss followed by a proud "yes!" gesture (forms a fist and elbow bent downwards) or in the case of a bad toss, avatar sighs and looks downwards. The second theme, positive reciprocation, was generated based on observing the interaction between participant pairs during play. For example, when player A made a good shot, player B would provide a compliment, and similarly, when player B was doing well, player A would also give praise in return. Enjoyment was particularly visible when players accept the compliment as indicated by a nod and smile. The third theme was developed from noticing participant expressions upon accomplishing a high score and winning a game. For example, when a participant wins, triumph is expressed by lifting both arms in the air followed by laughter. 
Reaction to avatar's animations. Participants expressed enjoyment when avatars introduced themselves and also when avatars expressed positive affect in response to participant's exceptional performance. By responding affectively, avatars seem to be reinforcing the participant's behaviour (i.e.: aim to toss a Bocce closer to the Pallino) and are encouraging enjoyment by persuading the player to feel a certain way. For example, when an avatar giggles, a participant also giggles. Moreover, signs of enjoyment were visible when participants made humorous comments in reaction to the avatar's actions during the introduction (i.e.: when avatar introduces him/herself, with an action, the participant would repeat the same action), tossing a Bocce, and winning, during the game. For example, after watching an avatar introduce herself, one participant said: "interesting introduction" and laughed, which could indicate enjoyment.

Aside from the introduction, the anticipated outcome of a toss seemed to also create some optimism for a number of participants. For example, in one competitive situation, after releasing a Bocce, the participant closely watched the avatar release it and the Bocce roll, then said: “Looks like I'm going to beat that (their opponent's Bocce), yes, I did!" and laughed. From this comment, there seemed to be an association between the avatar and the participant with respect to performance, suggesting that when the avatar expresses joy, the participant also expresses joy. Although performance may have been attributed to the participant's Bocce skills, the avatar's positive reaction to a good shot seemed to have contributed to a participant's feeling of enjoyment.

As for winning, when a player wins, the avatar performs a victory pose and participants expressed enjoyment watching it. For instance, in one cooperative playing scenario, when both players won, they mimicked the actions of the avatars, added a high-five, and one said: "let's play again!" In this particular case, it was conceivable that players had not only enjoyed themselves, but also felt motivated to proceed onto another game. This could be evidence that the avatar acts as a motivating factor and adds enjoyment to playing the game. However, if avatars were not present to provide this, the game experience could seem less rewarding because the player may not have felt instant reward.

Positive reciprocation. "Reciprocation" in the context of this experiment, means the interactions (both verbal and non-verbal) between participant pairs. For example, when player A 
smiles to player B, player B smiles in return. It was identified as an indication of enjoyment because it shows that participants were involved in the game, and interested in interacting with each other; otherwise, they may have not interacted with each other at all or expressed interest in the game they were playing. If they exchanged information with each other, it was likely they were engaged and enjoyed their time together.

This theme was particularly noticeable while participants were discussing strategies for winning and encouraging each other during play. In one cooperative scenario, player B asked player A for advice: "so do you think I should hit them out of the way or hit passed them?" Player A's response was: "I would probably go left and try to bounce it off the wall." Player B responded that they had not thought of that and demonstrated appreciation that player A had thought of such an approach. Then, player B tried it, and although it did not work, they both laughed - which indicated enjoyment. Encouragement was also reciprocated among players during the game. In one cooperative session, player A made a good shot and player B said: “nice." Similarly, when player B made a good shot, player A said: "that was like perfect" and player B replied: "thank you" and smiled. From this dialogue, when words of encouragement occurred between players, it seemed they enjoyed playing together. The game seemed to have invited social interaction and offered a platform for encouraging social support.

Reactions to winning. Lastly, winning was an extremely motivating factor during the game. Many participants expressed happiness after they had made a good shot and realized they had won. Particularly in the competitive (head-to-head) game scenarios, players would jump, laugh, and throw both arms up in the air to express enjoyment when they had made a good shot and had defeated the other player. Surprisingly, in several cooperative situations, when both players learned that they had lost against the other team (CPU avatars) they both laughed, which likely indicated they did not seem to mind losing. In fact, many indicated that the experience of losing was a motivator for playing again to attempt winning. From this observation, both winning and losing seems to be a motivator for continued play and in relation to one of the goals of this thesis, continuous play results in continuous exercise. 
One more interesting observation comes from noticing that participants seemed to be more upset about losing the game to CPU avatars as opposed to losing to a real person. This was particularly visible when several participants expressed frustration (shook head side-to-side and looked down) once they learned that the CPU avatars had won. Yet, in one case, when a participant learned that the other participant had won, the participant applauded the other participant. From this observation, there seems to be an emotional difference between losing to a machine versus another human being. Losing to a machine seemed to have elicited a negative response whereas losing to another human being seemed to have prompted a positive response. Participants responded in such a way possibly because if it was a human player, participants could have considered maintaining a decorous relationship with each other; however, it was perhaps not necessary to do so for a computer.

To summarize, the three themes extracted from the video recordings all seemed to have indicated some kind of enjoyment with respect to playing the game and playing with another player. From a psychological perspective, the outcome of winning or losing could promote intrinsic rewards for motivating continuous playing behaviours because for example, one may continue playing to experience the joy of winning. In contrast, social interaction could generate extrinsic rewards for motivating continuous play because one could have been influenced by the other player. 


\section{Discussion}

This study examined the effects of personality type and personality pairings for increasing the enjoyment and exercise motivation in a video gaming environment. It was hypothesized that those who played in a game scenario that matched their personality type would enjoy the game experience while those who played in a game scenario that did not match their personality type would not enjoy the game experience. In addition, it was also hypothesized that those who were paired with another person of a personality characteristic similar to their own would enjoy playing with that person. Yet, those who played with someone of a dissimilar personality type to their own would not enjoy playing with that person. Recall that the 8 hypotheses of this thesis were:

H1: A competitive individual will enjoy playing with another competitive individual H2: A cooperative individual will enjoy playing with another cooperative individual H3: A competitive individual will not enjoy playing with a cooperative individual H4: A cooperative individual will not enjoy playing with a competitive individual H5: A competitive individual will enjoy playing in a competitive game scenario H6: A cooperative individual will enjoy playing in a cooperative game scenario H7: A competitive individual will not enjoy playing in a cooperative game scenario H8: A cooperative individual will not enjoy playing in a competitive game scenario

From examining the effects of personality parings, results showed that $\mathrm{H} 2$ and $\mathrm{H} 6$ were supported in that a cooperative individual enjoyed playing with another cooperative individual and in a cooperative game scenario. Furthermore, results for effect of personality type showed that $\mathrm{H} 4$ was partially supported, in that a cooperative individual did not seem to enjoy playing with another individual regardless of the other player's personality type. H1 and H5 were somewhat supported in that it depends on gender. Competitive males would enjoy playing with a competitive individual in a competitive game scenario. $\mathrm{H} 3$ was not true in that competitive individuals enjoyed playing with another individual regardless of their opponent's personality type. $\mathrm{H} 7$ was rejected because results showed that a competitive individual enjoyed playing in a cooperative game scenario. Finally, H8 was partially untrue in that it depends on personality pairings because results showed that matched personality pairings enjoyed playing in a competitive game scenario more than a cooperative scenario. 


\section{Subjective Results}

Effect of Personality Type. Results showed that despite one's competitive or cooperative nature, a cooperative game scenario was less favourable. Results also suggest that competitive individuals did not enjoy playing with another person whereas cooperative individuals particularly enjoyed playing with another person. Additionally, the finding that cooperative individuals enjoyed playing with another player is further supported by results in the post-game questionnaire (Appendix D, Part B) through questions that evaluated the participant's perception of the other player. In both questions 8 and 12 (Table 10), competitive individuals responded rather negatively about the participant who they played with because they thought their partner was unhelpful and would be less likely to select the same person in a champion game. Thus, it seems that the presence of another player has a negative influence particularly for competitive individuals, yet a positive influence on cooperative individuals. It seems reasonable that cooperative individuals may enjoy playing a social game.

Effect of Personality Pairing. Results showed that matched personality pairings enjoyed playing in a competitive game scenario, and despite personality pairings, participants enjoyed playing with another person as evaluated by an intra-class correlation. From this finding, it seems that a competitive game is enjoyable when one plays with another person who possesses a personality similar to their own. For game design, a competitive game will likely maximize enjoyment only if personality pairings match; otherwise, a social game which offers interaction between participant pairs could also be enjoyable. Furthermore, results (Table 11) also showed that cooperative personality pairings particularly enjoyed playing together, and found each other supportive in a cooperative game scenario. Thus, to maximize enjoyment, video games should include a personality test and offer a game scenario consistent with one's personality.

Effect of Gender. Recall that male participants scored lower on both personality traits compared to female participants (Table 7) indicating that males were more competitive and cooperative. Results show that there were significant gender differences with respect to imposing a negative influence in the performance of each other. In particular, males felt that they could have performed better if they had played alone and found that the other player impeded their performance during the game. Considering the competitive nature in males it seems reasonable that they would have preferred individual gain because it would have possibly increased the 
likelihood of winning. Likewise, results also showed that male pairings favoured competitive play, and with respect to game design, a competitive game, would be most suitable for competitive males. In contrast, females appeared to enjoy both game scenarios because they reported that they were more likely to select the same player in a champion game. For females, they could have formed some kind of commitment or association with the other player; once they begin playing with a player, they continue playing with the same player. Furthermore, females would prefer playing with the same player in a champion game possibly because in a competitive game scenario, they found that it was easy to win or the other player was a good competitor while in a cooperative game scenario, they believe that choosing the same player would increase their likelihood of winning. Thus, to maximize enjoyment a video game, particularly an online game, can use gender pairings when a personality test is not possible. While this may not be optimal for the best game experience, it would improve the overall enjoyment over random pairings.

Effect of Relationship. Peng and Hsieh (2012) found that a cooperative goal structure within a multiplayer online game, friends shared more commitment between each other compared to strangers. However, the results of this study showed no significant differences for relationship with respect to game scenario preference, but did show that friends enjoyed playing together more than strangers. If players were strangers for each other to begin with, perhaps through matched personality pairings such as cooperative with cooperative and matched gender pairings for example, male with male, friendships may gradually develop which will hopefully result in more enjoyment.

Effect of Game Experience. There were significant differences in game experience with respect to the influence one player had on another. Less experienced participants felt more pressure to win because of the other player whereas more experienced participants felt less pressure to win because of the other player (see Table 16). For game design, perhaps the game may begin easy to allow beginners develop confidence. For game experts however, the game may adjust itself to match both the level of difficulty and player experience level in order to create an enjoyable game experience. Results also showed that regardless of whether participants had a lot or little game experience, they felt that the other player did not aid them in a cooperative game scenario and not a good competitor in a competitive game scenario. 


\section{Objective Results}

Time. Results showed that playing time in a competitive game scenario was longer than a cooperative scenario, yet not as a result of personality pairings. Since participants spent a longer period in a competitive game scenario, they could have enjoyed playing a competitive game more than a cooperative game. Thus, consistent with previous research (Vorderer, et al., 2003), competitive elements are imperative for experiencing enjoyment, and computer games should continue to offer competitive play as a playing option. Also, it could have been that a computer opponent moved faster than a human opponent because in a cooperative game scenario, participants had the option to not view the CPU avatars play.

Number of Rounds. The number of rounds did not appear to be an indication for more or less enjoyment in either a competitive or cooperative game scenario with respect to personality pairings. The lack of difference could imply that both game scenarios were equally enjoyable. Another possibility could be that the number of rounds participants played was more related to performance. Once a player wins, perhaps it was enough and he/she wanted to explore a different game scenario. Alternatively, a player could have also continued to experience winning again. However, when a player loses, he/she could have wanted a replay to attempt winning or discontinue because he/she may not want to experience losing again.

\section{Qualitative Observations}

From qualitative observations, participants expressed enthusiasm when they observed entertaining attributes on the screen, exchanged signs of encouragement and discovered they had won the game. From a design perspective, it would be best to create video games that invite positive interaction between players and emphasize winning. Additionally, from comments collected in the post-game questionnaire (Appendix D, Part C), one cooperative participant revealed that: enjoyment depends on the person whom they are playing with, and their desire to win and further explained that if they were playing against a friend, they would only want to surpass slightly because they wished to maintain decorum between the relationship; however, if it was their older brother, they would want to completely destroy him. Yet another competitive participant reported that they enjoyed the competitive aspects of the game, however in real life, they would prefer to work with people. From these two comments, and many others in the data alike, there seems to be various reasons that define enjoyment, not simply matched or 
mismatched personality pairings. Thus, it is important to consider multiple aspects of human behaviours and social situations for designing an enjoyable video game.

\section{Design Guidelines}

The findings of this study have several important implications for game design for maximizing enjoyment and engagement.

Table 19

Guidelines for Game Design

\begin{tabular}{|c|c|}
\hline Guideline & Supporting Evidence \\
\hline Suggest introducing a second player if a person is cooperative & Effect of personality type \\
\hline $\begin{array}{l}\text { Suggest not introducing a cooperative scenario if personality } \\
\text { type is competitive }\end{array}$ & Effect of personality type \\
\hline $\begin{array}{l}\text { Suggest a cooperative scenario if two player's possess } \\
\text { cooperative personality traits }\end{array}$ & Effect of personality pairings \\
\hline $\begin{array}{l}\text { Suggest not introducing another player if players possess } \\
\text { competitive personality traits }\end{array}$ & Effect of personality pairings \\
\hline Suggest a competitive scenario for male vs. male pairings & Effect of gender \\
\hline Suggest a competitive scenario for male vs. female pairings & Effect of gender \\
\hline Suggest a cooperative scenario for female vs. female pairings & Effect of gender \\
\hline Suggest any game scenario for friends & Effect of relationship \\
\hline Suggest emphasis on the importance of winning & Qualitative results \\
\hline Suggest opportunities for social interaction & Qualitative results \\
\hline
\end{tabular}

Furthermore, a personality test can be easily embedded into a massively multiplayer online role-playing game (MMORPG) such as Ultima Forever: Quest for the Avatar (Mythic: Electronic Arts Inc., 2013). During play, a player's personality can be detected throughout the game and the system automatically tailors the scenarios and recommends other players who are of similar personality types to increase the likelihood of experiencing enjoyment and engagement. The remainder of this thesis will address some caveats in the study and offer some directions for future research. 


\section{Conclusion}

Recall that the intention of this study was to investigate the usefulness of video games for encouraging exercise by comparing different personality type combinations in two multiplayer gaming scenarios. The personality type combinations consisted of matched (competitive vs. competitive and cooperative vs. cooperative) and mismatched (competitive vs. cooperative) pairings. The two gaming scenarios were competition and cooperation. In competition mode, two participants played against each other; whereas in cooperation mode, two participants formed a team and played against two computer avatars. The video game, Bocce, was especially selected because it offered the ideal playing situations for naturalistic observations of personality traits and social behaviours between participant pairs. This experiment provided statistical evidence that game enjoyment is related to one's personality type. A cooperative individual enjoys playing with another cooperative individual in a cooperative game scenario. Competitive individuals enjoy playing with other players regardless of the other player's personality type, but males in particular, enjoy a competitive game scenario whereas females enjoy a cooperative game scenario. Furthermore, qualitative observations suggested that enjoyment can be defined in numerous ways and thus, design considerations should reflect the diversity of enjoyment preferences.

However, there are a several limitations in this study. First, the sample size was relatively small. Also, the distributions of participant pairings were unequal - there were more mismatched $(N=17)$ compared to matched $(N=14)$ personality pairings. Perhaps a larger sample size, and balance in the personality pairings, for example thirty competitive pairs, thirty cooperative pairs and thirty mismatched pairs, would have achieved more statistical power. A second limitation was the game that was used for the experiment. Although it provided the optimal scenarios, the game itself was not physically demanding. Only simple wrist movements for tossing the ball and occasionally wandering around were sufficient for playing the game. Perhaps in a future study, a game with similar components for evaluating personality pairings, but require more physical exertion may be conducted and verify if the same results hold true. Another drawback of this study was it occurred in a laboratory setting with the use of a multimedia projector. To increase the ecological validity, perhaps a future experiment could be conducted using a television screen. 
Other suggestions for future work may explore other types of personality pairing possibilities such as combining an introvert with another introvert, extrovert with another extrovert, and an introvert with an extrovert. Perhaps introverted people would not initially enjoy playing with another person, but as they try on, an extrovert may motivate an introvert to continue play. Moreover, extroverted individuals may prefer a social game, whereas introverts may prefer to play alone. Aside from personality, culture could also influence one's preference for type of play. For example, North-American cultures may prefer competitive play but Asian cultures may favour cooperative play. Another possibility is this study examined personality pairings using a video game that was designed for indoors, so perhaps a follow-up study may evaluate the dynamics of personality pairings on enjoyment outdoors in a mobile context. And finally, more research is needed to examine the benefits of video games for motivating exercise relative to not only the effects of personality, but also environment (indoors vs. outdoors), relationship (friend vs. stranger), gender, and culture. 


\section{References}

Ahlgren, A., \& Johnson, D. W. (1979). Sex Difference in Cooperative and Competitive Attitudes from the $2^{\text {nd }}$ through the $12^{\text {th }}$ Grades. Developmental Psychology, 15(1), 45-49.

Alpert, P. T. (2009). Exercise Works. Home Health Care Management Practice, 21(5), 371-374.

Altamimi, R., \& Skinner, G. (2012). A Survey of Active Video Game Literature: From theory to technological application. International Journal of Computer and Information Technology, 1(1), 20-35.

Anderson-Hanley, C., Arciero, P. J., Brickman, A. M., Nimon, J. P., Okuma, N., Westen, S. C., Merz, M. E., Pence, B. D., Woods, J. A., Kramer, A. F., \& Zimmerman, E. A. (2012). Exergaming and Older Adult Cognition: A cluster randomized clinical trial. American Elsevier Inc.: Journal of Preventative Medicine, 42(2), 109-119.

Bassuk, S. S., \& Manson, J. E. (2005). Epidemiological Evidence for the Role of Physical Activity in Reducing Risk of Type 2 Diabetes and Cardiovascular Disease. Journal of Applied Physiology, 99, 1193-1204.

Bond Jr., C. F. (2001). Social Facilitation, Psychology of. International Encyclopedia of the Social \& Behavioural Sciences, 14290-14293.

Buman, M. P., Hekler, E. B., Bliwise, D. L., \& King, A. C. (2010). Exercise Effects on Night-toNight Fluctuations in Self-Rated Sleep Among Older Adults with Sleep Complaints. Journal of Sleep Research, 20(1), 28-37.

Caspersen, C. J., Powell, K. E., \& Christenson, G. M. (1985). Physical Activity, Exercise, and Physical Activity: Definitions and distinctions for health-related research. Public Health Report, 100-126. 
Deci, E. L., Betley, G., Kahle, J., Abrams, L., \& Porac, J. (1981). When Trying to Win: Competition and intrinsic motivation. Personality and Social Psychology Bulletin, 7(1), 79-83.

Deci, E. L., \& Ryan, R. M. (2000). The "What" and "Why" of Goal Pursuits: Human needs and the self-determination of behavior. Psychological Inquiry, 11(4), 227-268.

Deutsch, M. (1949). A Theory of Cooperation and Competition. Human Relations, 2, 129-151.

Frederick-Recascino, C. M., \& Schuster-Smith, H. (2003). Competition and Intrinsic Motivation in Physical Activity: A comparison of two groups. Journal of Sport Behaviour, 26(3), 240-254.

Gajadhar, B.J., de Kort, Y.A.W., \& IJsselsteijn, W.A. (2008). Shared Fun is Doubled Fun: Player enjoyment as a function of social setting. In P. Markopoulos et al. (Eds.), Fun and Games (p. 106-117). Springer-Verlag Berlin Heidelberg.

Ingledew, D. K., Markland, D., \& Ferguson, E. (2009). Three Levels of Exercise Motivation. Applied Psychology: Health and Well-Being, 1(3), 336-355.

Koivisto, A., Merilampi, S., \& Kiili, K. (2011). Mobile Exergames for Preventing Diseases Related to Childhood Obesity. Isabel '11, October 26-29, Barcelona, Spain, 1-5.

Li, F. (1999). The Exercise Motivation Scale: It's multifaceted structure and construct validity. Journal of Applied Sport Psychology, 11, 97-115.

MacCallum, R. C., Zhang, S., Preacher, K. J., \& Rucker, D. D. (2002). On the Practice of Dichotomization of Quantitative Variables. Psychological Methods, 7(1), 19-40.

Maitland, J., \& Siek, K. A. (2009). Technological Approaches to Promoting Physical Activity. OZCHI'09, Melbourne, Australia, 277-280. 
Murcia, J. A. M., Román, M. L. D, S., Galindo, C. M., Alonso, N., and González-Cutre, D. (2008). Peers' Influence on Exercise Enjoyment: A self-determination theory approach. Journal of Sports Science and Medicine, 7, 23-31.

Mythic: Electronic Arts Inc. (2013). Ultima Forever: Quest for the Avatar. Retrieved November 10, 2013, from http://www.ultimaforever.com/

Oliverira, R. D., \& Oliver, N. (2008). TripleBeat: Enhancing exercise performance with persuasion. Mobile HCI 2008, 255-264.

Owen, N., Healy, G. N., Matthews, C. E., \& Dunstan, D. W. (2010). Too Much Sitting: The population health science of sedentary behaviour. Exercise \& Sport Science Reviews, 38(3), 105-113.

Park, T., Yoo, C., Choe, S. P., Park, B., \& Song, J. (2012). Transforming Solitary Exercises into Social Exergames. CSCW'12, 1-4.

Peng, W., \& Crouse, J. (2013). Playing in Parallel: The effects of multiplayer modes in active video game on motivation and physical exertion. Cyberpsychology, Behaviour, and Social Networking, 16(6), 423-427.

Peng, W, Crouse, J. C., \& Lin, J. H. (2012). Using Active Video Games for Physical Activity Promotion: A systematic review of the current state of research. Health Education and Behaviour, 40(2), 171-192.

Peng, W., \& Hsieh, G. (2012). The Influence of Competition, Cooperation, and Player Relationship in a Motor Performance Centered Computer Game. Computers in Human Behaviour, 28, 2100-2106. 
Penko, A. L., \& Barkley, J. E. Motivation and Physiological Responses of Playing a Physically Interactive Video Game Relative to a Sedentary Alternative in Children. Springer: Annals of Behavioural Medicine, 39, 162-169. 2010.

Reckitt Benckiser. (2010). Lysol Disinfecting Wipes: Kills influenza a virus. Retrieved August 30, 2013, from http://www.lysol.ca/en/cleaning-products/disinfecting-wipes/disinfectingwipes-4in1

Reeve, J. (2005). Understanding Motivation and Emotion ( $4^{\text {th }}$ ed.). Hoboken, NJ: John Wiley and Sons, Inc.

Ryan, R.M., Frederick, C.M., Lepes, D., Rubio, N., \& Sheldon, K.M. (1997). Intrinsic motivation and Exercise Adherence. International Journal of Sport Psychology, 28, 335354.

Ryan, R. M., Williams, G. C., Patrick, H., \& Deci, E. L. (2009). Self-Determination Theory and Physical Activity: The dynamics of motivation in development and wellness. Hellenic Journal of Psychology, 6, 107-124.

Schmierbach, M., Xu, Q., Oeldorf-Hirsch, A., \& Dardis, F. E. (2012). Electronic Friend or Virtual Foe: Exploring the role of competitive and cooperative multiplayer video game modes in fostering enjoyment. Media Psychology, 15, 356-371.

Simmons, C. H., Wehner, E. A., Tucker, S. S., \& King, C. S. (1988). The Cooperative/Competitive Strategy Scale: A measure of motivation to use cooperative or competitive strategies for success. The Journal of Social Psychology, 128, 199-205.

Sinclair, J., Hingston, P., \& Masek, M. (2007). Considerations for the Design of Exergames. Proceedings of the 5th International Conference on Computer Graphics and Interactive Techniques in Australia and Southeast Asia, 289-296. 
Snyder, A. L., Anderson-Hanley, C., \& Arciero, P. J. (2012). Virtual and Live Social Facilitation While Exergaming: Competitiveness moderate exercise intensity. Journal of Sports \& Exercise Psychology, 34, 252-259.

Song, H., Kim, J., Tenzek, K. E., \& Lee, K. M. (2009). The Effects of Competition on Intrinsic Motivation in Exergames and the Conditional Indirect Effects of Presence. Proceedings of the 12th Annual International Workshop on Presence, Los Angeles, CA, 1-8.

Song, H., Kim, J., Tenzek, K. E., \& Lee, K. M. (2013). The Effects of Competition and Competitiveness upon Intrinsic Motivation in Exergames. Computers in Human Behaviour, 29, 1702-1708.

Sony Computer Entertainment America LLC. (2010). Sports Champions. San Diego Studio and Zindagi Games [PlayStation 3]. Tokyo, Japan: Sony Computer Entertainment, Inc.

Sports Champions. (2012) Retrieved July 19, 2013, from http://us.playstation.com/games/sportsps3.html.

Staiano, A. E., Abraham, A. A., \& Calvert, A. L. (2012). Motivating Effects of Cooperative Exergame Play for Overweight and Obese Adolescents. Journal of Diabetes Science and Technology, 6(4), 812-819.

Staiano, A. E., \& Calvert, S. L. (2011). The Promise of Exergames as Tools to Measure Physical Health. Entertainment Computing, 2(1), 17-21.

Sun, H. (In press). Impact of Exergames on Physical Activity and Motivation in Elementary School Students: A follow-up study. Journal of Sport and Health Science.

Tauer, J. M., \& Harackiewicz, J. M. (2004). The Effects of Cooperation and Competition in Intrinsic Motivation and Performance. Journal of Personality and Social Psychology, $86(6), 849-861$. 
Van Vugt, M., De Cremer, D., \& Janssen, D. P. (2007). Gender Differences in Cooperation and Competition: The male-warrior hypothesis. Psychological Science, 18, 19-23.

Vorderer, P., Hartmann, T., \& Klimmt, C. (2003). Explaining the Enjoyment of Playing Video Games: The role of competition. 2nd International Conference on Entertainment Computing, 1-9.

Yim, J., \& Graham, T.C.N. (2007). Using Games to Increase Exercise Motivation. Future Play 2007, 166-173.

Zajonc, R. B. (1965). Social Facilitation: A solution is suggested for an old unresolved social psychological problem. Science, New Series, 149(3681), 269-274.

Zindagi Games. (2013). Retrieved July 19, 2013, from: http://www.zindagigames.com/ 


\section{Appendices}

\section{Appendix A: Game Screen Shots}

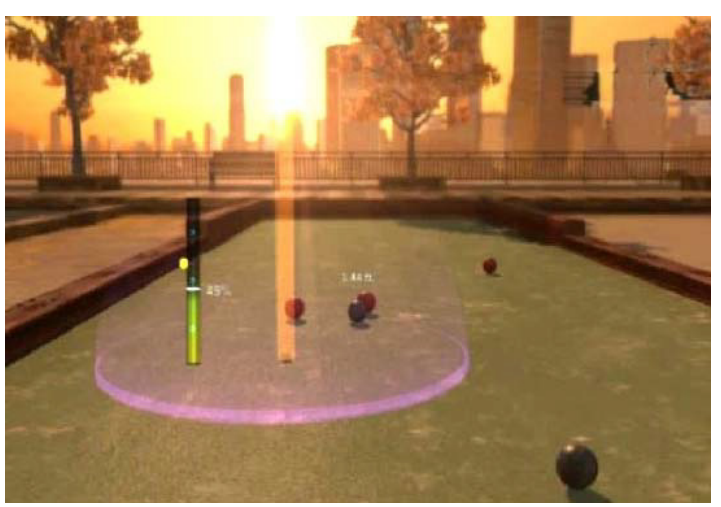

Figure A1. Close up of current gaming situation.

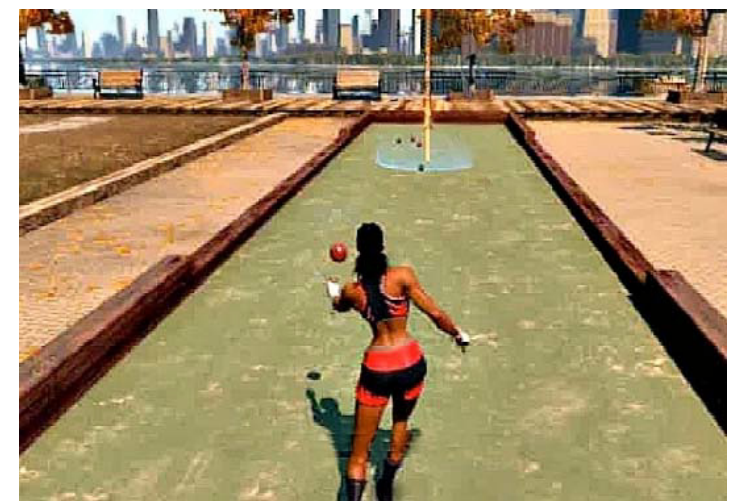

Figure A2. Avatar tossing ball into the court.

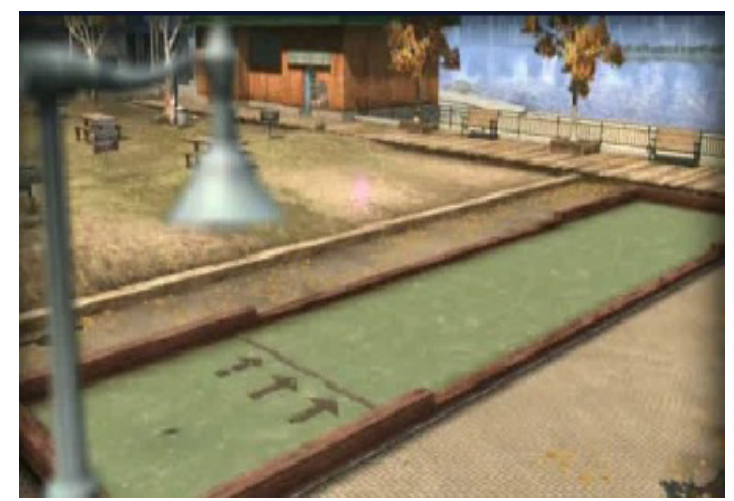

Figure A3. Open Court-I 
Appendix B: Social Game Study Recruitment Poster

\section{Want to play a video game?}

You will first complete a tutorial to learn about the game. Then, play the game with another person. After the game, you will complete a questionnaire. The study will take approximately 60 minutes and will be video recorded.

For more information, please contact Gerry Chan at socialgamestudy@gmail.com

Clearance Date: until May 31, 2013 Project \#: 13-1084
Social Game Study socialgamestudy@gmail.com Social Game Study socialgamestudy@gmail.com Social Game Study socialgamestudy@gmail.com Social Game Study socialgamestudy@gmail.com Social Game Study socialgamestudy@gmail.com Social Game Study socialgamestudy@gmail.com Social Game Study socialgamestudy@gmail.com Social Game Study socialgamestudy@gmail.com Social Game Study socialgamestudy@gmail.com Social Game Study socialgamestudy@gmail.com Social Game Study socialgamestudy@gmail.com Social Game Study socialgamestudy@gmail.com 


\section{Appendix C: Social Game Study E-mail Notice}

Dear Professor (name of Professor), I am currently conducting an experiment for the completion of my Master's thesis and was wondering if you would mind promoting it to your students? Below is a brief description about the experiment and they may contact me if they are interested or have any questions.

Thank you,

Gerry.

\section{WANT TO PLAY A VIDEO GAME?}

I am currently conducting user studies to evaluate the usability of the Sony PlayStation 3. No prior experience on using the system is necessary and your participation is completely voluntary. You will be asked to play a video game with another person called Bocce (Italian lawn bowling) created by Sony found in Sports Champions and answer a short survey afterwards. The study takes about an hour and is in the Azrieli Pavilion, room 234. Your actions will be video recorded for analysis purposes, but will be destroyed once the entire project is complete (approx. May 2013). Unfortunately, I do not have any funding for this research and so am not able to offer you any type of compensation such as money or course credit. If you're interested in participating, or have any further questions about the study, please do not hesitate to contact me at socialgamestudy@gmail.com.

Thank you and I look forward to hearing from you soon, Gerry. 


\section{Appendix D: Post-Game Questionnaire}

\section{Post-Game Questionnaire}

Part A: Demographical Information:

1. Age: years old.

2. Ethnicity:

3. Native Language:

4. Sex: $\square$ Male $\square$ Female

5. Have you ever played this game before?

6. Do you know the other player? $\square$ Yes $\square$ No
$\square$ Yes $\square$ No

7. On a scale of 1 (novice) to 10 (expert), how would you rate yourself with respect to your video gaming experience?

Novice

Expert

$\begin{array}{llllllllll}1 & 2 & 3 & 4 & 5 & 6 & 7 & 8 & 9 & 10\end{array}$

Part B: Please indicate your level of agreement with each of the following statements. $1=$ Strongly Disagree, $2=$ Disagree, $3=$ Somewhat Disagree, $4=$ Neither Agree or Disagree, $5=$ Somewhat Agree, $6=$ Agree, $7=$ Strongly Agree.

1. I thought the game was entertaining.

$\begin{array}{ccccccc}1 & 2 & 3 & 4 & 5 & 6 & 7 \\ \text { Strongly } & \text { Disagree } & \text { Somewhat } & \text { Neither } & \text { Somewhat } & \text { Agree } & \text { Strongly } \\ \text { Disagree } & & \text { Disagree } & \text { Agree or } & \text { Agree } & & \text { Disagree }\end{array}$

2. I liked playing on the same team.

$\begin{array}{ccccccc}1 & 2 & 3 & 4 & 5 & 6 & 7 \\ \text { Strongly } & \text { Disagree } & \text { Somewhat } & \text { Neither } & \text { Somewhat } & \text { Agree } & \text { Strongly } \\ \text { Disagree } & & \text { Disagree } & \text { Agree or } & \text { Agree } & & \text { Agree } \\ & & & \text { Disagree } & & & \end{array}$

3. I liked playing head-to-head.

$\begin{array}{ccccccc}1 & 2 & 3 & 4 & 5 & 6 & 7 \\ \text { Strongly } & \text { Disagree } & \text { Somewhat } & \text { Neither } & \text { Somewhat } & \text { Agree } & \text { Strongly } \\ \text { Disagree } & & \text { Disagree } & \text { Agree or } & \text { Agree } & & \\ & & & \text { Disagree } & & & \text { Agree }\end{array}$

4. I enjoyed playing with another person.

$\begin{array}{ccccccc}1 & 2 & 3 & 4 & 5 & 6 & 7 \\ \text { Strongly } & \text { Disagree } & \text { Somewhat } & \text { Neither } & \text { Somewhat } & \text { Agree } & \text { Strongly } \\ \text { Disagree } & & \text { Disagree } & \text { Agree or } & \text { Agree } & & \text { Agree } \\ & & & \text { Disagree } & & & \end{array}$


5. I thought that playing with another person was fun.

\begin{tabular}{|c|c|c|c|c|c|c|}
\hline 1 & 2 & 3 & 4 & 5 & 6 & 7 \\
\hline $\begin{array}{l}\text { Strongly } \\
\text { Disagree }\end{array}$ & Disagree & $\begin{array}{c}\text { Somewhat } \\
\text { Disagree }\end{array}$ & $\begin{array}{l}\text { Neither } \\
\text { Agree or } \\
\text { Disagree }\end{array}$ & $\begin{array}{c}\text { Somewhat } \\
\text { Agree }\end{array}$ & Agree & $\begin{array}{c}\text { Strongly } \\
\text { Agree }\end{array}$ \\
\hline
\end{tabular}

6. I enjoyed playing against another person.

$\begin{array}{ccccccc}1 & 2 & 3 & 4 & 5 & 6 & 7 \\ \text { Strongly } & \text { Disagree } & \text { Somewhat } & \text { Neither } & \text { Somewhat } & \text { Agree } & \text { Strongly } \\ \text { Disagree } & & \text { Disagree } & \begin{array}{c}\text { Agree or } \\ \text { Disagree }\end{array} & \text { Agree } & & \text { Agree } \\ & & & & & & \end{array}$

7. I thought that playing against another person was boring.

$\begin{array}{ccccccc}1 & 2 & 3 & 4 & 5 & 6 & 7 \\ \text { Strongly } & \text { Disagree } & \text { Somewhat } & \text { Neither } & \text { Somewhat } & \text { Agree } & \text { Strongly } \\ \text { Disagree } & & \text { Disagree } & \begin{array}{c}\text { Agree or } \\ \text { Disagree }\end{array} & \text { Agree } & & \text { Agree } \\ & & & & & \end{array}$

8. I felt that my partner was helpful when we were playing together against the computer.

\begin{tabular}{|c|c|c|c|c|c|c|}
\hline $\begin{array}{c}1 \\
\text { Strongly } \\
\text { Disagree }\end{array}$ & $\begin{array}{c}2 \\
\text { Disagree }\end{array}$ & $\begin{array}{c}3 \\
\text { Somewhat } \\
\text { Disagree }\end{array}$ & $\begin{array}{c}4 \\
\text { Neither } \\
\text { Agree or } \\
\text { Disagree }\end{array}$ & $\begin{array}{c}5 \\
\text { Somewhat } \\
\text { Agree }\end{array}$ & $\begin{array}{c}6 \\
\text { Agree }\end{array}$ & $\begin{array}{c}7 \\
\text { Strongly } \\
\text { Agree }\end{array}$ \\
\hline
\end{tabular}

9. I felt that my partner made more mistakes than I did.

$\begin{array}{ccccccc}1 & 2 & 3 & 4 & 5 & 6 & 7 \\ \text { Strongly } & \text { Disagree } & \text { Somewhat } & \text { Neither } & \text { Somewhat } & \text { Agree } & \text { Strongly } \\ \text { Disagree } & & \text { Disagree } & \begin{array}{c}\text { Agree or } \\ \text { Disagree }\end{array} & \text { Agree } & & \text { Agree } \\ & & & & & \end{array}$

10. I felt that my partner was a burden to me in the game.

\begin{tabular}{|c|c|c|c|c|c|c|}
\hline 1 & 2 & 3 & 4 & 5 & 6 & 7 \\
\hline $\begin{array}{l}\text { Strongly } \\
\text { Disagree }\end{array}$ & Disagree & $\begin{array}{c}\text { Somewhat } \\
\text { Disagree }\end{array}$ & $\begin{array}{l}\text { Neither } \\
\text { Agree or } \\
\text { Disagree }\end{array}$ & $\begin{array}{l}\text { Somewhat } \\
\text { Agree }\end{array}$ & Agree & $\begin{array}{c}\text { Strongly } \\
\text { Agree }\end{array}$ \\
\hline
\end{tabular}

11. I felt that the other person was a good competitor.

$\begin{array}{ccccccc}1 & 2 & 3 & 4 & 5 & 6 & 7 \\ \text { Strongly } & \text { Disagree } & \text { Somewhat } & \text { Neither } & \text { Somewhat } & \text { Agree } & \text { Strongly } \\ \text { Disagree } & & \text { Disagree } & \text { Agree or } & \text { Agree } & & \text { Agree } \\ & & & \text { Disagree } & & & \end{array}$

12. I would pick the same partner, if I was playing a champion game.

$\begin{array}{ccccccc}1 & 2 & 3 & 4 & 5 & 6 & 7 \\ \text { Strongly } & \text { Disagree } & \text { Somewhat } & \text { Neither } & \text { Somewhat } & \text { Agree } & \text { Strongly } \\ \text { Disagree } & & \text { Disagree } & \text { Agree or } & \text { Agree } & & \text { Agree } \\ & & & \text { Disagree } & & & \end{array}$


13. I felt pressured to win because of the other person.

\begin{tabular}{|c|c|c|c|c|c|c|}
\hline 1 & 2 & 3 & 4 & 5 & 6 & 7 \\
\hline Strongly & Disagree & Somewhat & Neither & Somewhat & Agree & Strongly \\
\hline Disagree & & Disagree & $\begin{array}{l}\text { Agree or } \\
\text { Disagree }\end{array}$ & Agree & & Agree \\
\hline
\end{tabular}

14. I was motivated to play better because of the other person.

$\begin{array}{ccccccc}1 & 2 & 3 & 4 & 5 & 6 & 7 \\ \text { Strongly } & \text { Disagree } & \text { Somewhat } & \text { Neither } & \text { Somewhat } & \text { Agree } & \text { Strongly } \\ \text { Disagree } & & \text { Disagree } & \text { Agree or } & \text { Agree } & & \text { Agree } \\ & & & \text { Disagree } & & \end{array}$

15. I would like to play with this person again.

\begin{tabular}{|c|c|c|c|c|c|c|}
\hline $\begin{array}{c}1 \\
\text { Strongly } \\
\text { Disagree }\end{array}$ & $\begin{array}{c}2 \\
\text { Disagree }\end{array}$ & $\begin{array}{c}3 \\
\text { Somewhat } \\
\text { Disagree }\end{array}$ & $\begin{array}{c}4 \\
\text { Neither } \\
\text { Agree or } \\
\text { Disagree }\end{array}$ & $\begin{array}{c}5 \\
\text { Somewhat } \\
\text { Agree }\end{array}$ & $\begin{array}{c}6 \\
\text { Agree }\end{array}$ & $\begin{array}{c}7 \\
\text { Strongly } \\
\text { Agree }\end{array}$ \\
\hline
\end{tabular}

16. I could have played better on my own.

\begin{tabular}{|c|c|c|c|c|c|c|}
\hline $\begin{array}{c}1 \\
\text { Strongly } \\
\text { Disagree }\end{array}$ & $\begin{array}{c}2 \\
\text { Disagree }\end{array}$ & $\begin{array}{c}3 \\
\text { Somewhat } \\
\text { Disagree }\end{array}$ & $\begin{array}{c}4 \\
\text { Neither } \\
\text { Agree or } \\
\text { Disagree }\end{array}$ & $\begin{array}{c}5 \\
\text { Somewhat } \\
\text { Agree }\end{array}$ & $\begin{array}{c}6 \\
\text { Agree }\end{array}$ & $\begin{array}{c}7 \\
\text { Strongly } \\
\text { Agree }\end{array}$ \\
\hline
\end{tabular}

17. I would have rather played alone.

\begin{tabular}{|c|c|c|c|c|c|c|}
\hline 1 & 2 & 3 & 4 & 5 & 6 & 7 \\
\hline $\begin{array}{l}\text { Strongly } \\
\text { Disagree }\end{array}$ & Disagree & $\begin{array}{l}\text { Somewhat } \\
\text { Disagree }\end{array}$ & $\begin{array}{l}\text { Neither } \\
\text { Agree or } \\
\text { Disagree }\end{array}$ & $\begin{array}{c}\text { Somewhat } \\
\text { Agree }\end{array}$ & Agree & $\begin{array}{l}\text { Strongly } \\
\text { Agree }\end{array}$ \\
\hline
\end{tabular}

18. Using the Move Motion Controller to throw balls felt realistic.

\begin{tabular}{|c|c|c|c|c|c|c|}
\hline 1 & 2 & 3 & 4 & 5 & 6 & 7 \\
\hline $\begin{array}{l}\text { Strongly } \\
\text { Disagree }\end{array}$ & Disagree & $\begin{array}{c}\text { Somewhat } \\
\text { Disagree }\end{array}$ & $\begin{array}{l}\text { Neither } \\
\text { Agree or } \\
\text { Disagree }\end{array}$ & $\begin{array}{c}\text { Somewhat } \\
\text { Agree }\end{array}$ & Agree & $\begin{array}{c}\text { Strongly } \\
\text { Agree }\end{array}$ \\
\hline
\end{tabular}

19. The scenery of the court was visually appealing.

\begin{tabular}{|c|c|c|c|c|c|c|}
\hline $\begin{array}{c}1 \\
\text { Strongly } \\
\text { Disagree }\end{array}$ & $\begin{array}{c}2 \\
\text { Disagree }\end{array}$ & $\begin{array}{c}3 \\
\text { Somewhat } \\
\text { Disagree }\end{array}$ & $\begin{array}{c}4 \\
\text { Neither } \\
\text { Agree or } \\
\text { Disagree }\end{array}$ & $\begin{array}{c}5 \\
\text { Somewha } \\
\text { Agree }\end{array}$ & $\begin{array}{c}6 \\
\text { Agree }\end{array}$ & $\begin{array}{c}7 \\
\text { Strongly } \\
\text { Agree }\end{array}$ \\
\hline
\end{tabular}

20. The on screen instructions were hard to understand.

$\begin{array}{ccccccc}1 & 2 & 3 & 4 & 5 & 6 & 7 \\ \text { Strongly } & \text { Disagree } & \begin{array}{c}\text { Somewhat } \\ \text { Disagree }\end{array} & & \begin{array}{c}\text { Neither } \\ \text { Disagree }\end{array} & \begin{array}{c}\text { Agree or } \\ \text { Disagree }\end{array} & \text { Agree } \\ & & & & \text { Agree } & \text { Strongly } \\ \text { Agree }\end{array}$


Comparing Personality Types in a Video Game Context 57

21. The menus were easy to understand.

$\begin{array}{ccccccc}1 & 2 & 3 & 4 & 5 & 6 & 7 \\ \text { Strongly } & \text { Disagree } & \text { Somewhat } & \text { Neither } & \text { Somewhat } & \text { Agree } & \text { Strongly } \\ \text { Disagree } & & \text { Disagree } & \begin{array}{c}\text { Agree or } \\ \text { Disagree }\end{array} & \text { Agree } & & \text { Agree } \\ & & & & & & \end{array}$

22. I felt that the tutorial was adequate for the game.

$\begin{array}{ccccccc}1 & 2 & 3 & 4 & 5 & 6 & 7 \\ \text { Strongly } & \text { Disagree } & \text { Somewhat } & \text { Neither } & \text { Somewhat } & \text { Agree } & \text { Strongly } \\ \text { Disagree } & & \text { Disagree } & \text { Agree or } & \text { Agree } & & \text { Agree } \\ & & & \text { Disagree } & & & \end{array}$

23. After playing Bocce in virtual reality, I want to try playing it in the real world.

$\begin{array}{ccccccc}1 & 2 & 3 & 4 & 5 & 6 & 7 \\ \text { Strongly } & \text { Disagree } & \begin{array}{c}\text { Somewhat } \\ \text { Disagree }\end{array} & & \begin{array}{c}\text { Neither } \\ \text { Disagree }\end{array} & \begin{array}{c}\text { Agree or } \\ \text { Disagree }\end{array} & \text { Agree } \\ & & & & \text { Agree } & \text { Strongly } \\ \text { Dgree }\end{array}$


Personality Questionnaire (Simmons, Wehner, Tucker, \& King, 1988)

Part C: Please select the number on the scale that most accurately reflects your response to each statement. 1 = Always, 2 = Usually, $3=$ Sometimes, $4=$ Rarely, $5=$ Never.

1. It is important to me to do better than others.

$\begin{array}{ccccc}1 & 2 & 3 & 4 & 5 \\ \text { Always } & \text { Usually } & \text { Sometimes } & \text { Rarely } & \text { Never }\end{array}$

2. Success is not very important to me.

$\begin{array}{ccccc}1 & 2 & 3 & 4 & 5 \\ \text { Always } & \text { Usually } & \text { Sometimes } & \text { Rarely } & \text { Never }\end{array}$

3. Individual success can be achieved while working with others.

$\begin{array}{ccccc}1 & 2 & 3 & 4 & 5 \\ \text { Always } & \text { Usually } & \text { Sometimes } & \text { Rarely } & \text { Never }\end{array}$

4. People who are successful face a constant struggle to remain successful.

$\begin{array}{ccccc}1 & 2 & 3 & 4 & 5 \\ \text { Always } & \text { Usually } & \text { Sometimes } & \text { Rarely } & \text { Never }\end{array}$

5. By achieving success I also get other things which are important to me.

$\begin{array}{ccccc}1 & 2 & 3 & 4 & 5 \\ \text { Always } & \text { Usually } & \text { Sometimes } & \text { Rarely } & \text { Never }\end{array}$

6. To succeed, one must compete against others.

$\begin{array}{ccccc}1 & 2 & 3 & 4 & 5 \\ \text { Always } & \text { Usually } & \text { Sometimes } & \text { Rarely } & \text { Never }\end{array}$

7. Joint effort is the best way to achieve success.

$\begin{array}{ccccc}1 & 2 & 3 & 4 & 5 \\ \text { Always } & \text { Usually } & \text { Sometimes } & \text { Rarely } & \text { Never }\end{array}$

8. People who succeed are more likely to have satisfying lives.

$\begin{array}{ccccc}1 & 2 & 3 & 4 & 5 \\ \text { Always } & \text { Usually } & \text { Sometimes } & \text { Rarely } & \text { Never }\end{array}$

9. Success is something I am willing to work hard for.

$\begin{array}{ccccc}1 & 2 & 3 & 4 & 5 \\ \text { Always } & \text { Usually } & \text { Sometimes } & \text { Rarely } & \text { Never }\end{array}$

10. The costs of success are often much greater than the rewards.

$\begin{array}{ccccc}1 & 2 & 3 & 4 & 5 \\ \text { Always } & \text { Usually } & \text { Sometimes } & \text { Rarely } & \text { Never }\end{array}$

11. To succeed, one must cooperate with others.

$\begin{array}{ccccc}1 & 2 & 3 & 4 & 5 \\ \text { Always } & \text { Usually } & \text { Sometimes } & \text { Rarely } & \text { Never }\end{array}$


12. Success is only achieved through individual effort.

$\begin{array}{ccccc}1 & 2 & 3 & 4 & 5 \\ \text { Always } & \text { Usually } & \text { Sometimes } & \text { Rarely } & \text { Never }\end{array}$

13. People who succeed often lead unhappy lives.

$\begin{array}{ccccc}1 & 2 & 3 & 4 & 5 \\ \text { Always } & \text { Usually } & \text { Sometimes } & \text { Rarely } & \text { Never }\end{array}$

14. I enjoy the challenge of competing against others to succeed.

$\begin{array}{ccccc}1 & 2 & 3 & 4 & 5 \\ \text { Always } & \text { Usually } & \text { Sometimes } & \text { Rarely } & \text { Never }\end{array}$

15. Success is best achieved through cooperation rather than through competition.

$\begin{array}{ccccc}1 & 2 & 3 & 4 & 5 \\ \text { Always } & \text { Usually } & \text { Sometimes } & \text { Rarely } & \text { Never }\end{array}$

16. The rewards of success outweigh the costs.

$\begin{array}{ccccc}1 & 2 & 3 & 4 & 5 \\ \text { Always } & \text { Usually } & \text { Sometimes } & \text { Rarely } & \text { Never }\end{array}$

17. Success is my major goal in life.

$\begin{array}{ccccc}1 & 2 & 3 & 4 & 5 \\ \text { Always } & \text { Usually } & \text { Sometimes } & \text { Rarely } & \text { Never }\end{array}$

18. I am happier when I am not striving to succeed.

$\begin{array}{ccccc}1 & 2 & 3 & 4 & 5 \\ \text { Always } & \text { Usually } & \text { Sometimes } & \text { Rarely } & \text { Never }\end{array}$

19. In the end, cooperation with others is not compatible with success.

$\begin{array}{ccccc}1 & 2 & 3 & 4 & 5 \\ \text { Always } & \text { Usually } & \text { Sometimes } & \text { Rarely } & \text { Never }\end{array}$

20. In order to be successful, one has to be willing to give up too many other important aspects of life.

$\begin{array}{ccccc}1 & 2 & 3 & 4 & 5 \\ \text { Always } & \text { Usually } & \text { Sometimes } & \text { Rarely } & \text { Never }\end{array}$

21. Success can best be defined as a situation in which there are both winners and losers.

$\begin{array}{ccccc}1 & 2 & 3 & 4 & 5 \\ \text { Always } & \text { Usually } & \text { Sometimes } & \text { Rarely } & \text { Never }\end{array}$

22. I feel better about myself when I am working toward success.

$\begin{array}{ccccc}1 & 2 & 3 & 4 & 5 \\ \text { Always } & \text { Usually } & \text { Sometimes } & \text { Rarely } & \text { Never }\end{array}$


23. Shared efforts can lead to both individual and group success.

$\begin{array}{ccccc}1 & 2 & 3 & 4 & 5 \\ \text { Always } & \text { Usually } & \text { Sometimes } & \text { Rarely } & \text { Never }\end{array}$

24. I enjoy working with others to achieve joint success.

$\begin{array}{ccccc}1 & 2 & 3 & 4 & 5 \\ \text { Always } & \text { Usually } & \text { Sometimes } & \text { Rarely } & \text { Never }\end{array}$

Finally, please provide any additional comments you may have.

Thank you for your participation! 


\section{Appendix E: Game Scenario Descriptions}

Competitive Scenario. Sony Sports Champions refers to this type of game scenario "head-to-head". It is played by 2 human players and requires the use of 2 Move MotionControllers - one for player 1 and another one for player 2. The game begins by player 1 setting the Pallino (it must land beyond a white line; otherwise, player 2 will be prompted to set the Pallino) and tossing one Bocce immediately after. Then, player 2 has 4 chances to try and toss a Bocce closer to the Pallino than player 1. If player 2 only takes one toss to get a Bocce closer than player 1, player 1 gets to go again. However, if after the $4^{\text {th }}$ try, player 2 is still not able to beat player 1, player 1 receives a multipoint chance if he/she is able to toss a Bocce as close to or anywhere in between the Pallino as his/her first toss. Player 1 always begins the first round and the player who wins the previous round gets the honour of setting the Pallino in the next round. To gain points, each player's aim is to toss a Bocce closer to the Pallino than their opponent. The player who accumulates the most points wins.

Cooperative Scenario. Sony Sports Champions titles this type of game scenario "same team". Similar to the competitive scenario, it is also played by 2 human players and requires 2 controllers. The difference is 2 human players form a team and play against 2 computer avatars which Sony calls "CPU". To begin the game, player 1 tosses the Pallino, followed by a Bocce and then, it is the avatar's turn to toss. Each team has 4 tries and both avatars continue tossing until a Bocce lands closer to the Pallino than player 1's Bocce. Once an avatar's Bocce is closer to the Pallino than player 1's, it is player 2's turn. The first round continues until both teams have tossed all their Bocces and consecutive rounds progress by the team who won the previous round gets the honour of tossing the Pallino in the next round. Points are earned by getting a Bocce closer to the Pallino than the opponents. The team who scores the most points wins. It is possible to skip, and not watch the avatars play by pressing the "select" button.

More information regarding how the game works is available at: http://sportschampions.wikia.com/wiki/Bocce 


\section{Appendix F: Pre-Experiment Consent Form}

\section{Informed Consent Form}

The purpose of an informed consent is to ensure that you understand the purpose of the study and the nature of your involvement. The informed consent has to provide sufficient information such that you have the opportunity to determine whether you wish to participate in the study.

Study Title: An Evaluation of Preferences for Social Games

\section{Research Personnel:}

\begin{tabular}{|l|l|l|}
\hline Gerry Chan & Dr. Anthony Whitehead & Dr. Avi Parush \\
Principal Investigator & Faculty Advisor & Faculty Advisor \\
gerrychan@cmail.carleton.ca & (613) 520-2600 ext.1696 & (613) 520-2600 ext.6026 \\
& Anthony_Whitehead@carleton.ca & Avi_Parush@carleton.ca \\
\hline
\end{tabular}

Expiration date for the collection of data: 31 May 2013 (renewable)

Purpose: To test the usability of the Sony PlayStation3 and find ways for improving the design of video games.

Task Requirements: You will first complete a tutorial to learn about the game. Then, play the game with another person. After the game, you will complete a questionnaire.

Duration and Locale: The study will take approximately 60 minutes and will be video recorded. It will take place in room 234 in the Azrieli Pavilion at Carleton University.

Potential Risk/Discomfort: There will be no psychological or physical risk, beyond any risk normally involved in using computer video gaming systems.

Anonymity/Confidentiality: The data will be kept anonymous and confidential. All data will be coded such that your name is not associated with the data. Only the research personnel directly involved with this experiment will have access to the data. All data and video recordings will be destroyed once the research project is completed.

Right to Withdraw: You can refuse to answer any individual question and you have the right to withdraw from this experiment at any time. 
This study has received clearance by the Carleton University Research Ethics Board (Project \#: 13-1084).

If you have any ethical concerns about this study, you may contact:

Professor Andy Adler, Chair or Prof. Louise Heslop, Vice-Chair

Carleton University Research Office

Carleton University

Ottawa, Ontario, K1S 5B6

Telephone: (613) 520-2517 or E-mail: ethics@carleton.ca

I have read the above description of the experiment and understand the conditions of my participation. My signature indicates that I agree to participate in this experiment.

Name of Participant

Name of Researcher
Signature of Participant

Signature of Research
Date

Date 


\section{Appendix G: Post-Experiment Consent Form}

\section{Post Experiment Consent Form}

This consent form is to inform you the exact nature of the study and ask for your permission to use the data collected.

Study Title: $\quad$ An Evaluation of Personality Types for Social Games

Clearance Date: until May 31, 2013

Project \#: $\quad 13-1084$

Research Personnel:

\begin{tabular}{|l|l}
\hline Gerry Chan & Dr. Anthony Whitehead
\end{tabular}

Principal Investigator gerrychan@cmail.carleton.ca

Faculty Advisor

(613) 520-2600 ext. 1696

Anthony_Whitehead@carleton.ca
Dr. Avi Parush Faculty Advisor (613) 520-2600 ext. 6026

Avi_Parush@carleton.ca

Purpose of Research:

The purpose of this experiment is to study the usefulness of video games for motivating people to engage in physical activity by combining people with different or similar personality types. Instead, it was presented as a usability test to evaluate the effectiveness of the Sony PlayStation 3 and a video game called Bocce created by Sony found in Sports Champions. The use of deception was necessary in this experiment because we are interested in measuring personality and so it was important to create an environment in order to observe natural behaviours as much as possible.

Confidentiality:

For the duration of the entire research project, all data and video recordings will be locked in this lab and will be erased once this study is completed.

If you have any questions about this research project, you may contact any one of the research personnel listed above.

If you have any ethical concerns, you may contact the Carleton Research Ethics Board:

Professor Andy Adler, Chair or Prof. Louise Heslop, Vice-Chair

Carleton University Research Office

Carleton University

Ottawa, Ontario, K1S 5B6

Telephone: (613) 520-2517 or E-mail: ethics@carleton.ca

I have been fully debriefed by the experimenter, have had the opportunity to read this consent form, and have been given the opportunity to ask questions about this research project. As a result,

please discard all data collected.

I give permission to have my data in this research project.

Name of Participant

Name of Researcher
Signature of Participant

Signature of Research

\section{Date}

Date 


\section{Appendix H: Debriefing Form}

\section{Debriefing Form}

Study Title: $\quad$ An Evaluation of Preferences for Social Games

Clearance Date: until May 31, 2013

Project \#: $\quad$ 13-1084

The purpose of this experiment is to study the effectiveness of video games for motivating people to engage in exercise. By comparing different combinations of personality types, we are evaluating the compatibility between cooperative vs. competitive, competitive vs. competitive, and cooperative vs. cooperative individuals. The video game, Bocce, was especially selected to create a competitive or cooperative scenario. We hypothesize those with personalities alike, for example both are competitive individuals, would enjoy playing competitively and as a result, are more likely to continue exercise.

Your thoughts, comments, and opinions will be taken into consideration in making design recommendations. Thank you for participating in this study. Your time and effort are greatly appreciated!

If you have any further questions regarding this research, please contact:

\begin{tabular}{|l|l|l|}
\hline Gerry Chan & Dr. Anthony Whitehead & Dr. Avi Parush \\
Principal Investigator & Faculty Advisor & Faculty Advisor \\
Carleton University & $\begin{array}{l}\text { Carleton University } \\
\text { (613) 520-2600, ext.: 1696 }\end{array}$ & $\begin{array}{l}\text { Carleton University } \\
\text { (613) 520-2600, ext.: 6026 }\end{array}$ \\
gerrychan@cmail.carleton.ca & Anthony_Whitehead@,carleton.ca & Avi_Parush@carleton.ca \\
\hline
\end{tabular}

If you have concerns about the ethics of this research, please contact:

Dr. Andy Adler

Chair, Carleton University Ethics

Committee

Carleton University

(613) 520-2517

ethics@,carleton.ca
Dr. Louise Heslop

Vice-Chair, Carleton University Ethics

Committee

Carleton University

(613) 520-2517

ethics@carleton.ca

Finally, we would appreciate it if you do not speak to your fellow colleagues about this study since some of them may participate in future studies related to video games. 
Comparing Personality Types in a Video Game Context 66

Appendix I: Observations Record Sheet
Participant Pairs:
$\&$
[ ] Competitive $\rightarrow$ Cooperative [ ] $\overline{\text { Cooperative }} \rightarrow \overline{\text { Competitive }}$

$\underline{\text { Observations Record }}$

[ ] Competitive [ ] Cooperative

\begin{tabular}{|l|l|l|l|}
\cline { 2 - 5 } \multicolumn{1}{c|}{} & \multicolumn{2}{c|}{ Individual } & Both \\
\hline Measure & Participant A & & \\
\hline Facial Expressions & & & \\
\hline Gestures & & & \\
\hline Language & & & \\
& & & \\
\hline
\end{tabular}

[ ] Competitive [ ] Cooperative

\begin{tabular}{|l|l|l|l|}
\cline { 2 - 5 } \multicolumn{1}{c|}{} & \multicolumn{2}{c|}{ Individual } & Both \\
\hline Measure & Participant A & & \\
\hline Facial Expressions & & & \\
\hline Gestures & & & \\
\hline & & & \\
& & & \\
\hline
\end{tabular}

Additional Notes: 
Comparing Personality Types in a Video Game Context 67

\section{Appendix J: Testing Script}

Before the experiment, ask if the participant has epilepsy; if they do, disqualify them. Introduction:

Hello, and welcome to the Human-Computer Interaction Laboratories. My name is Gerry, and I will be conducting the usability testing today. For the duration of the study, please keep in mind that I am testing the effectiveness of the software, not your ability. So, if you run into problems or things are not going well, please don't feel bad. It is a problem with the software, not you. Before we begin, this is a consent form [show participant consent form]. Once you have read and understood the consent form, please sign it and return it to me [provide consent form].

The video game the both of you will be playing today is called: "Bocce" - basically, it is a ball tossing game. The game begins by one player tossing a "Pallino" - which is a small golden ball, into an empty court which sets a marker. Then, players try to toss larger balls, called Bocce, as close to the Pallino as they can. The person or team who tosses a Bocce closest to the Pallino wins!

Do you have any questions so far?

If not, let's move over to the projector [invite participants over to the projector].

\section{Practice Session:}

First of all, I would like to ask if any of you have used the Sony PlayStation before?

[If the answer was yes, also ask: may I also ask if you have played this game before?]

[If the answer was no, say: not to worry, you will have some practice before you start playing.]

[During the tutorial, use only one controller].

[hold MoveMotion Controller and stand in front of the cart].

This is called a MoveMotion Controller. It serves 2 functions. During play, it is the Booce. Now, it is like a remote control for you to navigate through the menus and select commands. Now, I will show you both how it works and then let you try on your own.

[Point to the "select" button]

This center button here is the main selection button, you press it when you wish to confirm a selection - it is kind of like the "Enter" key on a computer keyboard. The purple circle on the screen is the cursor - just like the arrow that represents the mouse on a computer. [Turn MoveMotion Controller around]. This little button here located behind the controller is the back button, but the system refers to it as the "T" button.

Now, I will press the select button to select "Bocce", "Free Play (1-4 Players)", "Learn to Play", and "Introduction to Bocce". I am right handed, so I select "right", and complete a calibration procedure - here, I follow exactly the actions of the avatar - click once by my side, another time up against my shoulder, down again, and lastly buckle. Now I will set the "Pallino" by tossing it into the court. To grab the ball, you press the back button. When you wish to let go of the ball, you let go of the button. Do you see how it works? Do you have any questions?

You may use this red "X" [show tape on the floor] as a reference point for where to stand throughout the game.

Now it's your turn to try. You are player 1 and you will be player 2 [give player 1 the controller]. There are 4 tries. If you [player 1] can please try 2 , and then when you have finished, please hand the controller to him/her [player 2] and let him/her try 2. 
[Stand to the side of screen to ensure participants are using the controller correctly].

[Once participants are through with the introduction, take controller and proceed to the next tutorial: "Aiming, Movement, and Ball spin"].

Ok, great! Do you have any questions? If not, there is just one more tutorial called: "Aiming, Movement and Ball Spin." May I please have the controller? Thank you. Now, I will exit, and select "Aiming, Movement and Ball Spin." You may position the avatar by holding the "select" button and repositioning it like this. Next, it is also possible to move the avatar by pressing the "red circle" button and dragging the controller like this. To get a closer view of the current situation, you may press the "green triangle" and it will zoom in for you. Do you see how all of these buttons work? Ok, now I will let the both of you try spinning the ball. [Hand controller to player 1]. Once again, there are 4 tries. If you can please try 2 and then when you're done, if you can please hand the controller to player 2 so that he/she may try 2. [Stand to the side of the screen and point to the avatar]. Here, you need to bend your arms and kind of turn you wrist inwards, just like the avatar is doing.

[When participants have successfully completed the tutorial, say:]

Ok, great! Do you have any questions?

Setup and Play:

Now, would the both of you mind wearing a heart rate monitor?

[Clean with Lysol wipes and give each participant a heart rate monitor].

[If participants refuse to wear one, continue the study without it].

The plastic piece faces outwards and the strap goes around your chest, underneath your clothing. The washrooms are just outside and you may go to put it on.

[Once participants return, place watch on their wrist, ask them to stand apart from each other, ensure "heart rate monitor detected", and begin timer].

[Remind player roles and hand each participant a controller].

Once again, you are "player 1" [purple] and you are "player 2" [blue].

There are 2 types of playing scenarios. One of them is "head-to-head" and the other is "same team". The two of you will have the opportunity to play in both scenarios. In each playing scenario, there are a total of 8 rounds, but you do not have to complete all of them. After each round, the both of you may decide to continue or stop. If you decide to continue, simply click next. If you decide to stop, please tell me and I will reset the game. While the both of you are playing, I will be observing and taking some notes in the background.

Do you have any questions?

*** To initiate the game, please select "Bocce". Now, select "Free Play (1-4 players)", the first court location, 2 players, [head to head; same team], your hand preference, "silver" for level of difficulty, an avatar [if male, select Conner; if female, select Belle], and finally the calibration procedure please.

As stated in the consent form, the experiment will be video recorded, but will be erased once the entire research project is over [walk over to video camera and press "record"]. I am going to begin the recording and you may start playing now.

[Reset game and repeat instructions from: ***].

[Once participants finish, remember to collect the controllers, heart rate monitors and stop video recording]. 
Post-Game Questionnaire and Closing:

This is a post-game questionnaire. Please complete it and return it to me when you are done. [Ensure participants are sitting away from each other when completing the survey].

Do you have any questions?

This experiment was not really about testing the usability of the Sony PlayStation 3. In fact, it was to study the usefulness of video games for motivating exercise and personality types. This is a post-experiment consent form [show participants the form]. It explains the true purpose of the experiment [provide post experiment consent form]. After you have read it, please decide if it is alright with you to use the data collected or not and sign it.

Do you have any questions?

This concludes the experiment.

Thank you for your time and this is a debriefing form to tell you a little more about the study [provide debriefing form]. If you have any further question, please feel free to contact me or any research personnel listed on this sheet. If you have any concerns related to ethics, please feel free to contact the ethics committee [dismiss participants]. Thank you again, I really appreciate it. 


\section{Appendix K: Avatar Information}

Male participants were asked to select an avatar named Connor, while females were asked to select "Belle". Below are the original profiles provided by Sony Sports Champions for each of them [Source: http://sportschampions.wikia.com/wiki/Category:Avatars].

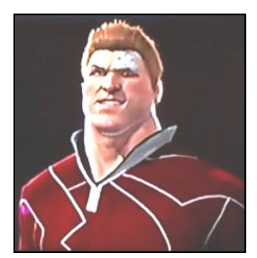

Connor

Age / Sex: 31, Male

Height / Weight: $172 \mathrm{~cm}, 230$ lbs

Home: Dublin, Ireland

Primary Sport: Rugby

Strengths: Strength, Agility

Despite his lack of great height, or perhaps even because of it, Conner pushes himself relentlessly and has built a reputation as one of the toughest players in Irish rugby. Nicknamed "The Green Hammer" by the press for his ferocious play style, he's a ferocious competitor whose aggressive style can border on vicious. Connor's energy and perfectionism drive him to compete and provide himself time and time again.

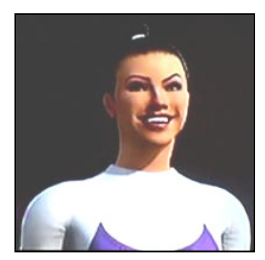

\section{Belle}

Age / Gender: 18, Female

Height / Weight: $162 \mathrm{~cm}, 105 \mathrm{lbs}$

Home: Bucharest, Romania

Primary Sport: Gymnastics

Strengths: Agility, Speed

While certainly one of the most determined contestants, Belle's driven nature sometimes gets out of hand. Forced into a state-run gymnastics program from an extremely young age, Belle never really developed the normal behavior and social skills of other girls her age and instead focused all her efforts on winning. Groomed from the outset to be an Olympic Champion, she sees the competition as a waste of time and is only here to maintain favor with the directors of her school. Feisty and bratty, she has an enormous sense of entitlement and only makes friends when she needs something. 
Appendix L: Histograms for Questions 2 - 17 (Part B) in the Post-Game Questionnaire

Questions 2 - 17 (Part B) in the post-game questionnaire (Appendix D) evaluated the level of agreement using a 1 (strongly disagree) to 7 (strongly agree) point Likert scale.

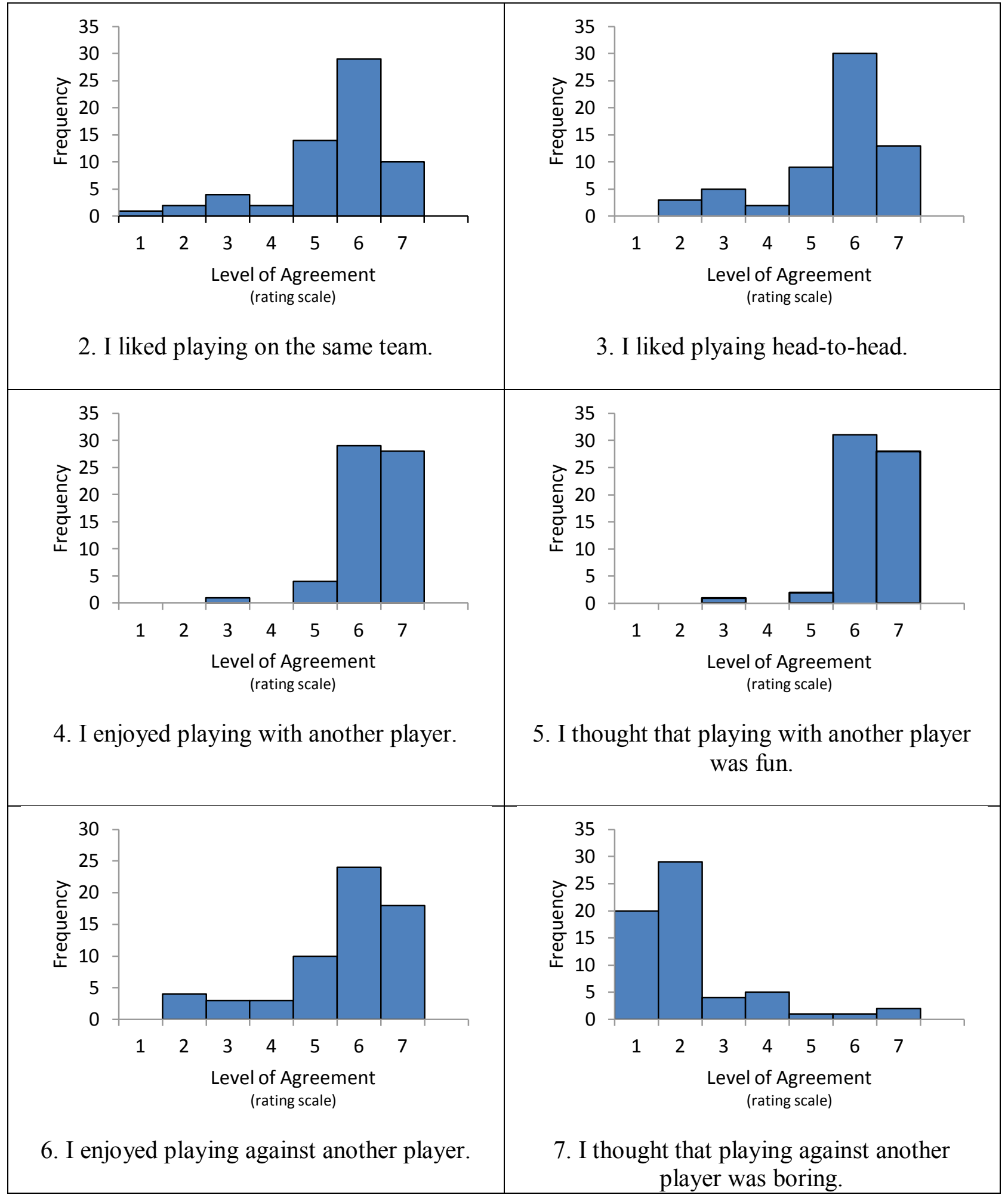




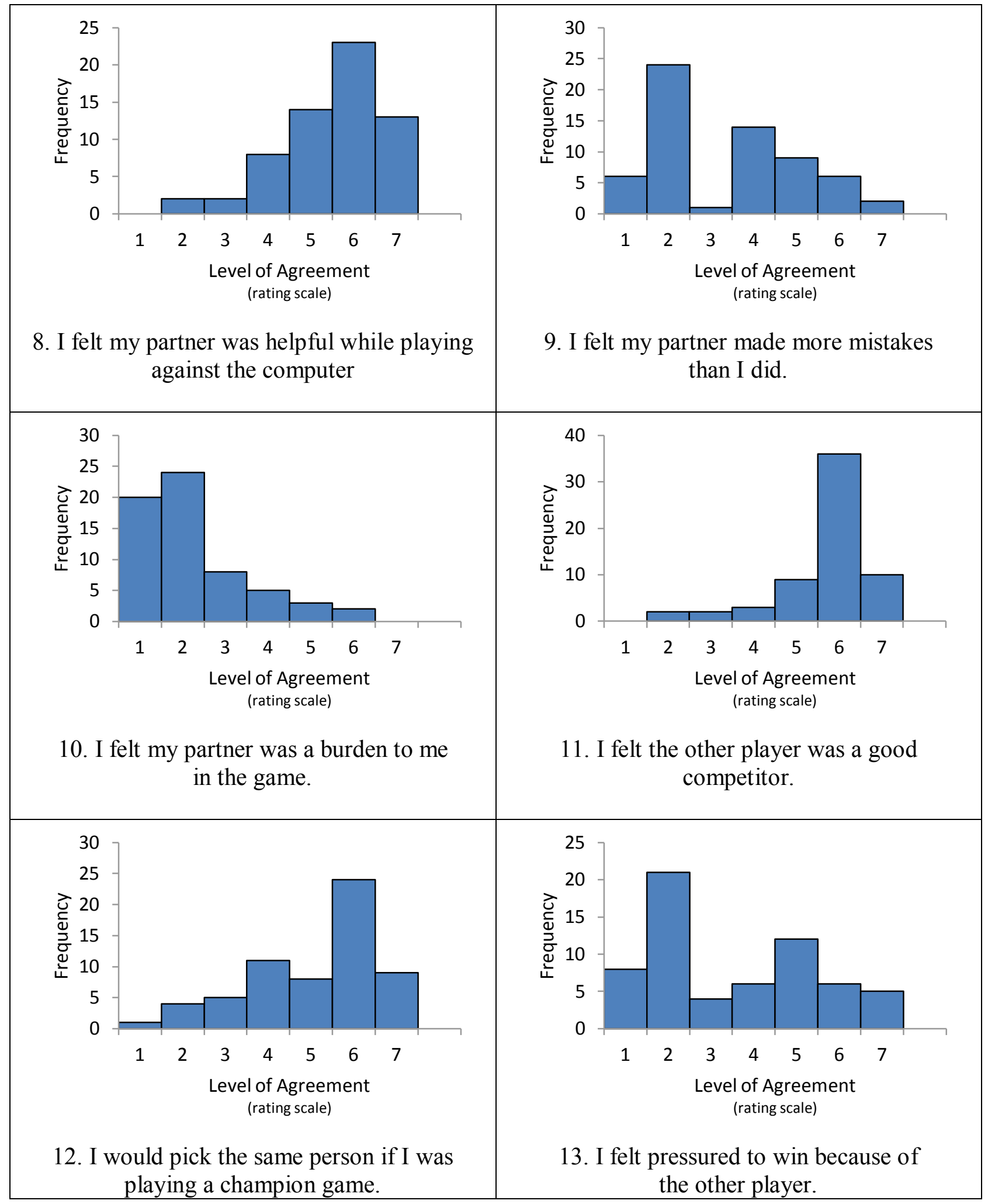




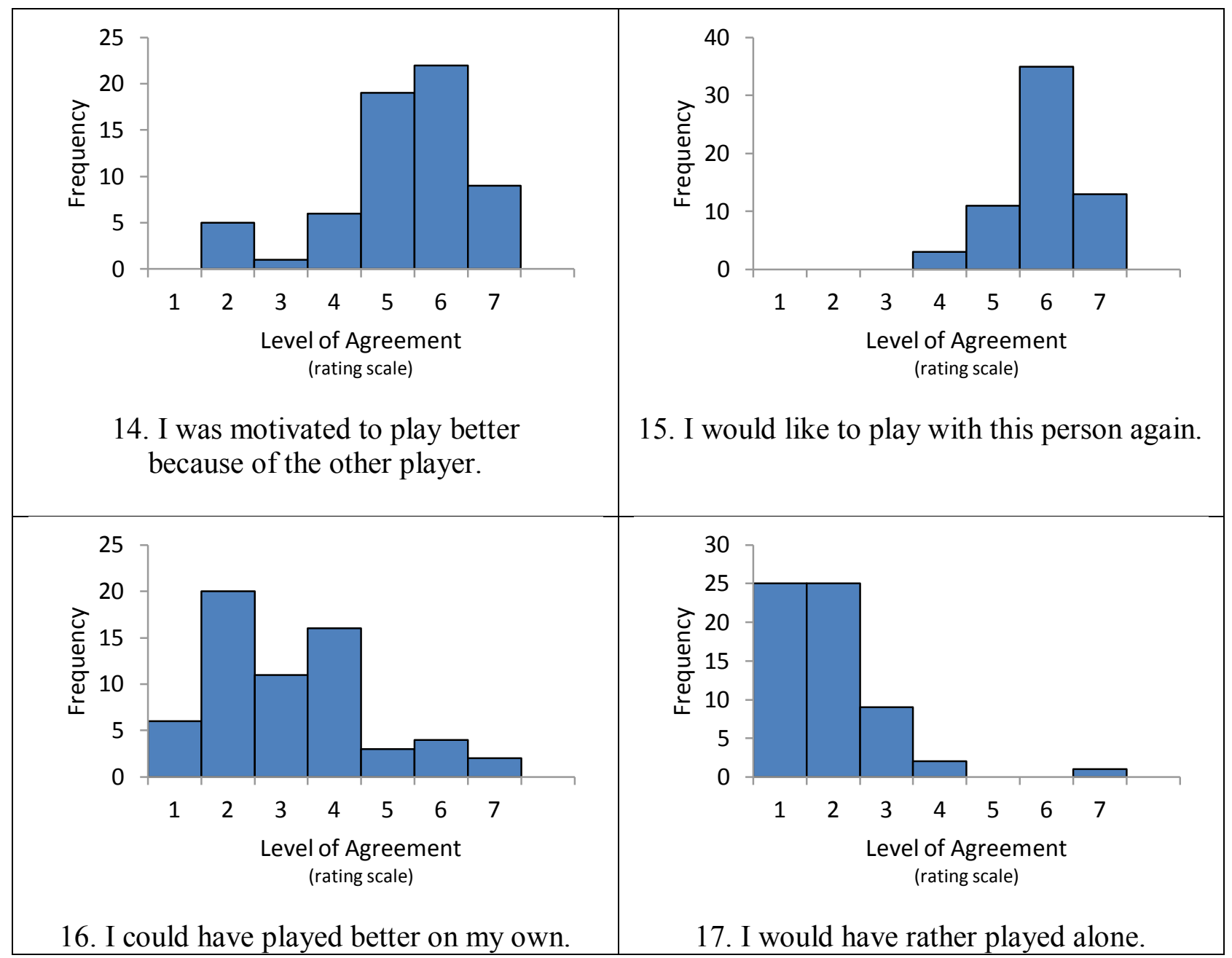

